IZA DP No. 5624

Understanding Social Interactions:

Evidence from the Classroom

Giacomo De Giorgi

Michele Pellizzari

April 2011 


\title{
Understanding Social Interactions: Evidence from the Classroom
}

\author{
Giacomo De Giorgi \\ Stanford University, \\ NBER and SCID \\ Michele Pellizzari \\ Bocconi University, IGIER \\ and IZA
}

\section{Discussion Paper No. 5624 \\ April 2011}

IZA

P.O. Box 7240

53072 Bonn

Germany

Phone: +49-228-3894-0

Fax: +49-228-3894-180

E-mail: iza@iza.org

Any opinions expressed here are those of the author(s) and not those of IZA. Research published in this series may include views on policy, but the institute itself takes no institutional policy positions.

The Institute for the Study of Labor (IZA) in Bonn is a local and virtual international research center and a place of communication between science, politics and business. IZA is an independent nonprofit organization supported by Deutsche Post Foundation. The center is associated with the University of Bonn and offers a stimulating research environment through its international network, workshops and conferences, data service, project support, research visits and doctoral program. IZA engages in (i) original and internationally competitive research in all fields of labor economics, (ii) development of policy concepts, and (iii) dissemination of research results and concepts to the interested public.

IZA Discussion Papers often represent preliminary work and are circulated to encourage discussion. Citation of such a paper should account for its provisional character. A revised version may be available directly from the author. 
IZA Discussion Paper No. 5624

April 2011

\section{ABSTRACT \\ Understanding Social Interactions: Evidence from the Classroom}

There is a large literature on social interactions and still little is known about the economic mechanisms leading to the high level of clustering in behavior that is so commonly observed in the data. In this paper we present a model in which agents are allowed to interact according to three distinct mechanisms, and we derive testable implications on the mean and the variance of the outcomes within and across groups. The empirical tests allow us to distinguish which mechanism(s) generates the observed patterns in the data. In our application we study the performance of undergraduate students and we find that social interactions take the form of mutual insurance. Such a result bears crucial policy implications for all those situations in which social interactions are important, from teamwork to class formation in education and co-authorship in academic research.

JEL Classification: J0, 121

Keywords: social interactions, peer effects, teamwork

Corresponding author:

Giacomo De Giorgi

Department of Economics

Stanford University

579 Serra Mall

94305-6072 Stanford, CA

USA

E-mail: degiorgi@stanford.edu

\footnotetext{
* We thank Richard Blundell, Pat Bayer, Joan de Marti, Matt Harding, Caroline Hoxby, Matt Jackson, Pat Klein, Enrico Moretti, Eleonora Patacchini, Jesse Rothstein and seminar participants at UCBerkeley, NBER SI 2010, UCLA, UC-Davis, Universitá di Bologna, Stockholm University, Uppsala University. We are also grateful to Bocconi University for allowing access to their archives. In particular Giacomo Carrai, Mariele Chirulli, Mariapia Chisari, Alessandro Ciarlo, Enrica Greggio, Gabriella Maggioni, Erika Palazzo, Giovanni Pavese, Cherubino Profeta, Alessandra Startari and Mariangela Vago have all been a constant source of precious help and information. The usual disclaimer applies.
} 


\section{Introduction}

There is a firm belief that social interactions are important determinants of behavior in a variety of contexts (Matthew O. Jackson 2008, Matthew O. Jackson 2009), yet very little is known about the mechanics of such interactions. We propose and test models of social interactions where risk-averse agents engage in production and can either (i) act in isolation, (ii) exploit possible complementarities (joint production), or (iii) mutually insure against idiosyncratic shocks to time or productivity.

These models lend testable predictions in the first and second moments of the distribution of outcomes that allow us to distinguish them in empirical applications. In particular, while all three mechanisms generate outcomes that are correlated within groups, they have different implications for the average performance of group members.

We consider the model in which agents act in isolation, but may care about each others' performance (absent explicit social interactions), as a benchmark and we compare the implications of joint production and insurance against it. We show that under joint production agents exploit complementarities to achieve a higher level of output compared to the benchmark. In the mutual full insurance scenario, any idiosyncratic difference in productivity or endowments across agents is eliminated and the within-group comparisons that induced higher effort in the benchmark case disappears. As a consequence average output is lower in mutual (full) insurance than in the benchmark case.

Despite the fact that our three mechanisms generate different predictions for average performance, they all lead to clustering of outcomes within groups, which is what is commonly referred to as peer effects or social interactions. Under decentralization (i.e. our benchmark model) such a result rests on the assumption that agents evaluate their performance relative to their peers, as in a tournament or status seeking model (Sherwin Rosen 1986, George A. Akerlof 1997). Namely, the utility one enjoys out of a good performance declines if everyone in the group does well. When agents produce jointly, the effort levels of all members of the group enter each other's production functions, thus inducing correlation in outcomes. Finally, 
in the mutual insurance setting the heterogeneity due to the idiosyncratic shocks is eliminated, thus mechanically reducing the dispersion of outcomes within groups. Additionally, agents also exert similar effort levels.

In our model agents choose their optimal level of effort conditional on the idiosyncratic shock, while the choice of the interaction mechanism is made beforehand under uncertainty according to a standard von Neumann-Morgenstern expected utility function. We further assume that there are costs associated to active social interactions, such as those required to produce jointly or to engage in mutual insurance, and that such costs decrease as agents get to know each other. Consistently with this framework, in our empirical application we examine how the mean and the dispersion of outcomes evolve with the frequency of students' meetings in the classroom.

We test the implications of our model using data on undergraduate students at Bocconi University, who are randomly assigned to teaching classes. Moreover, the random allocation is repeated at the beginning of each academic year, so that the data exhibit a large degree of exogenous variation (both cross-sectionally and over time) in the number of hours any two students spend together in the same classroom. We exploit such exogenous variation to test the implications of the interaction mechanisms considered in our theoretical discussion on the mean and the variance of academic performance, both cross-sectionally and over time.

Our results indicate that mutual insurance is the economic mechanism that prevails in the setting of our application. Specifically, we find that pairs of students who are allocated to the same classes more often are characterized by less dispersed outcomes (both cross-sectionally and over time) and lower average performance. Of the three mechanisms considered, insurance is the only one capable of producing both of these results. As an additional test of insurance, we also find that the likelihood that the grade vectors of any two students cross decreases with the number of hours they have been randomly allocated to the same classes. Such a result is consistent with the mutual insurance mechanism, which preserves the ranking of agents' outcomes across states and time.

To our knowledge, we are amongst the first to explicitly investigate the economic nature of 
social interactions. The literature has been dominated by the search for suitable identification strategies to solve the many econometric hurdles of peer effects models (Charles F. Manski 1993, William A. Brock \& Steven N. Durlauf 2001, Robert Moffitt 2001) and has, so far, devoted very little attention to understanding the different mechanisms that may generate such effects. ${ }^{1}$ One notable exception is Jane Cooley (2009), who looks at a series of theoretical models to derive the empirical functional forms of spill-overs across classmates. A different approach is taken by Alberto Bisin, Andrea Moro \& Giorgio Topa (2009), who discuss the identification of models of social interactions in the presence of multiple equilibria in a setting where the economic mechanism is not directly investigated.

Although we test the implications of our models in the higher education environment, the set-up and topics discussed in this paper are quite general and can be applied to many other areas. For example, in a production team the pressure exerted by the social group, either through sanctions or simple relative utility (Eugene Kandel \& Edward P. Lazear 1992), may alleviate the free-riding problem (Armen Alchian \& Harold Desmetz 1972, Bengt Holmstrom 1982). Peer pressure also explains the results of Alexandre Mas \& Enrico Moretti (2009), where supermarket checkers' performance improve when they are paired with high performance checkers. Similarly, peer pressure seems to provide a consistent explanation also for the findings in Armin Falk \& Andrea Ichino (2006). ${ }^{2}$

A key difference between our theoretical approach and the typical model of team production is the verifiability of (individual) output by the principal. Consistently with the empirical application, in our model individual performance is verifiable, there are no (explicit) principals nor informational asymmetries, however agents face an uncertain environment characterized by random shocks to their time endowment or to their productivity. We believe that many production problems resemble the one studied in this paper, from manufacturing to construction, to most white collar jobs or coauthoring in academic research, where tenure decisions are made

\footnotetext{
${ }^{1} \mathrm{~A}$ recent wave of studies has approached the identification problem with the use of network structures (Yann Bramoullé, Habiba Djebbari \& Bernard Fortin 2009, Coralio Ballester, Antoni Calvó-Armengol \& Yves Zenou 2006, Giacomo De Giorgi, Michele Pellizzari \& Silvia Redaelli 2010).

${ }^{2}$ Oriana Bandiera, Iwan Barankay \& Imran Rasul (2009a) show how social connections affect productivity in teams; while Patrick Bayer, Randi Pintoff \& David Pozen (2009) provide evidence on the underlying nature of the interaction in criminal behavior, suggesting a mechanism based on information or learning from others.
} 
at the individual level but the research activity is often carried out within groups of co-authors.

Without knowledge of the mechanics of social interactions it is often impossible to foresee the effects of any policy intervention. A notable example is Scott Carrell, Bruce I. Sacerdote \& James E. West (2010), whose experiment on optimal sorting based on reduced form parameters leads to unexpected and unintended results. In this view, the policy implications of our paper are far-reaching. In our application, for example, if the aim of the policy maker is to maximize average performance, one would design a mechanism of class allocation that prevents students from meeting too frequently and/or introduces incentives to favor joint production and limits the possibility of mutual insurance. In the case of teamwork, the incentives provided by the principal need to account for the possible risk-sharing behavior among team members (Kandel \& Lazear 1992, Bandiera, Barankay \& Rasul 2009a, Oriana Bandiera, Iwan Barankay \& Imran Rasul 2009b).

The structure of the paper is as follows: Section 2 presents our three simple models of social interactions (decentralization, joint production and mutual insurance); in Section 3 we provide a description of the data used in Section 4 to carry out the empirical exercise and take the predictions of the model to the test. Section 5 briefly discusses alternative mechanisms and, finally, Section 6 concludes.

\section{Model}

In this section we present a simple model of social interactions. For expositional purposes and coherence with the empirical application, we will frame the model in the education environment and characterize the two agents as students and the production process as learning. Otherwise, the model can be applied to any setting with social interactions and it is meant to parsimoniously include the key features of several interaction mechanisms and to produce testable implications that can be taken to the data.

Two risk averse, ex-ante identical students $(i, j)$ exert costly effort to study, learn and obtain a grade in academic tests or exams. Students value high academic performance. For 
simplicity, we assume that all tests are identical and we exclude the possibility that good performance in one exam affects later performance. ${ }^{3}$ Students are hit by idiosyncratic shocks to their endowment of time or to their productivity. Effort is chosen conditional on such shocks, an assumption that, combined with the lack of interlinks across exams, implies that the choice of effort is completely static.

Additionally, agents are allowed to interact according to three different mechanisms: (i) decentralization or no explicit interactions (Section 2.1); (ii) joint production (Section 2.2); (iii) mutual (full) insurance (Section 2.3). The choice of the mode of interaction is made before observing the realizations of the shocks on the basis of a standard von Neumann-Morgenstern expected utility function. We further assume that active interactions, either in the form of joint production or mutual insurance, are costly and that such costs decrease with how well students know each other. The choice of the mode of interaction can be revised for each exam, for example when the lectures begin.

In the remaining of this section, after describing briefly the building blocks of the model, we first consider the solution of the static choice of optimal effort under the three mechanisms that we consider (Sections 2.1, 2.2 and 2.3). Then, in Section 2.4, we discuss the choice of the mode of interaction. For simplicity, we analyze the non-strategic equilibrium of the model and later, in Section 2.5, we present some extensions, including strategic behavior, multiple agents and the social planner solution.

Before moving to the presentation of the model, it is worth emphasizing that the theoretical analysis in this section is crucial for the purpose of uncovering the mechanics of social interactions empirically. It is only by comparing the empirical implications derived from the different models that we can identify the nature of the interactions in the data. A mere empirical analysis without the derivation of a formal model would be incapable of producing any interesting insight into the proposed mechanisms, as the standard regression of individual over group performance would capture a feature that is common to all the economic mechanisms that we consider, a similar argument would apply to a covariance analysis (Bryan S. Graham 2008).

\footnotetext{
${ }^{3}$ The model could easily accommodate interlinks across academic tests and the qualitative implications would remain unchanged.
} 
Utility function. The utility of the generic student $i$ depends positively on her academic performance $x_{i}$ and negatively on effort $e_{i}$. Moreover, we assume two additional properties of the utility function. First, students are risk averse, a property that generates the desire to insure against fluctuations in academic performance. Second, the individual returns to $x_{i}$ (might) decrease with one's peer performance $x_{j}$, i.e. the utility derived from an $\mathrm{A}$ is lower when everyone gets an A. Alternative interpretations of this assumption are that students are averse to equality or feel the peers' pressure. We parameterize this relative utility effect with a loading factor $\gamma \in(0, \bar{\gamma})$ that multiplies $x_{j}$ in $i$ 's utility and vice versa. Thanks to this assumption the model delivers within group correlation of the outcomes, even in the absence of explicit interactions. Eventually, we will work with the following static utility function: ${ }^{4}$

$$
U_{i}=\ln \left(x_{i}-\gamma x_{j}\right)-e_{i}
$$

Production/Learning function. Academic performance is the output of a learning/production process, whose inputs are effort (possibly of both agents) and time $t_{i}$, combined according to the following technology:

$$
x_{i}=t_{i} g\left(e_{i}, e_{j}\right)
$$

While the level of effort is endogenously chosen by the student, time is an exogenous factor subject to idiosyncratic shocks. ${ }^{5}$ In this interpretation, it is natural to assume that the two

\footnotetext{
${ }^{4}$ There is a corresponding and symmetric function for agent $j$. Obviously, $\gamma$ is bounded above by $\bar{\gamma}$ to guarantee that $x_{i}>\gamma x_{j}$ and $x_{j}>\gamma x_{i}$. The choice of the particular (concave) utility function and the static framework are not crucial for the testable implications produced.

${ }^{5}$ The production function of human capital might clearly include other inputs, such as teachers, resources, class size and class composition, to name just a few. However, to keep the model simple and coherent with the empirical application, we focus solely on effort and time. Adding additional inputs that are controlled by the education institution would only complicate the notation, while in the empirical analysis we can fully control for all these additional factors.
} 
production factors are complementary to some degree (not perfect substitutes). ${ }^{6}$ We assume:

$$
\begin{aligned}
& \frac{\partial g\left(e_{i}, e_{j}\right)}{\partial e_{i}}>0, \quad \frac{\partial g\left(e_{i}, e_{j}\right)}{\partial e_{j}} \geq 0 \quad \text { (production is non-decreasing in efforts); } \\
& \frac{\partial^{2} g\left(e_{i}, e_{j}\right)}{\partial^{2} e_{i}}<0, \quad \frac{\partial^{2} g\left(e_{i}, e_{j}\right)}{\partial^{2} e_{j}} \leq 0 \quad \text { (production is non-convex in efforts); } \\
& \frac{\partial^{2} g\left(e_{i}, e_{j}\right)}{\partial e_{i} \partial e_{j}}>0, \quad \text { (positive cross-partial derivatives or complementarity of efforts); } \\
& \frac{\partial g\left(e_{i}, e_{j}\right)}{\partial e_{i}}>\frac{\partial g\left(e_{i}, e_{j}\right)}{\partial e_{j}}, \quad \text { (marginal product of own effort larger than that of peer). }
\end{aligned}
$$

When students do not cooperate, $e_{j}$ does not enter the production function for $x_{i}$ and for notational convenience we label $g\left(e_{i}, 0\right)$ as $f\left(e_{i}\right)$ :

$$
x_{i}=t_{i} g\left(e_{i}, 0\right)=t_{i} f\left(e_{i}\right)
$$

Shocks. Time is equal to a fixed (maximum) endowment normalized to 1 and we allow for a negative shock of size $\epsilon$ to arrive with probability $\frac{1}{2}$ and $t_{i}=1+u_{i}$. The shock hits only one person in the $\{i, j\}$ couple, so that with probability $\frac{1}{2}$, we have $u_{i}=0$ and $u_{j}=-\epsilon$ and with probability $\frac{1}{2}$ we have $u_{i}=-\epsilon$ and $u_{j}=0$. This is equivalent to assuming that the shocks to $t$ are perfectly negatively correlated between the two agents. This stochastic endowment process could be easily generalized and the results would remain qualitatively unchanged as long as some degree of idiosyncratic variation is maintained. The most intuitive interpretation of the shock is absence due to illness or random distraction in the classroom. Although one could alternatively interpret $t$ as some simple (stochastic) productivity parameter, we find our previous interpretation more convenient for expositional purposes.

\subsection{Decentralized solution}

When students act in isolation they maximize their utility taking each other's behavior as given. Even in this simple version, our model still has the potential to generate peer effects through

\footnotetext{
${ }^{6}$ We could also work with a more complicated function $g\left(e_{i}, t_{i}, e_{j}, t_{j}\right)$, but the derivation becomes more tedious without any real additional insight. This is due to the fact that $t_{i}$ and $t_{j}$ are exogenous factors.
} 
relative utility (or equality aversion).

Without loss of generality, we will assume throughout the paper that agent $i$ has a positive shock $\left(t_{i}=1\right)$ and $j$ has a negative one $\left(t_{j}=1-\epsilon\right)$ :

$$
\begin{aligned}
U_{i} & =\ln \left[f\left(e_{i}\right)-\gamma(1-\epsilon) f\left(e_{j}\right)\right]-e_{i} \\
U_{j} & =\ln \left[(1-\epsilon) f\left(e_{j}\right)-\gamma f\left(e_{i}\right)\right]-e_{j}
\end{aligned}
$$

Both agents choose their optimal effort level (under decentralization) $e_{a}^{D}, \forall a=i, j$ conditional on the realizations of the shocks according to the following first order conditions:

$$
\begin{array}{r}
\frac{\partial f\left(e_{i}^{D}\right)}{\partial e_{i}}=f\left(e_{i}^{D}\right)-\gamma(1-\epsilon) f\left(e_{j}^{D}\right) \\
(1-\epsilon) \frac{\partial f\left(e_{j}^{D}\right)}{\partial e_{j}}=(1-\epsilon) f\left(e_{j}^{D}\right)-\gamma f\left(e_{i}^{D}\right)
\end{array}
$$

Notice that equations 10 and 11 characterize a non-strategic equilibrium where agents do not internalize the effect of their choices on their peers. In Section 2.5 we will return to this point.

Concavity in the utility function leads to the following result:

Proposition 1 The optimal effort level is not smaller for the student affected by the negative shock: $e_{i}^{D} \leq e_{j}^{D}$, with equality holding when $\gamma=0$.

The proof is in Appendix A.

From proposition 1 , it is immediate to derive the following, which is a direct consequence of optimality:

Proposition 2 The performance/grade of the student hit by a positive shock is larger than that obtained by the student with a negative shock, i.e. $x_{i}^{D}>x_{j}^{D}$, where $x_{i}^{D}$ and $x_{j}^{D}$ are the equilibrium outcomes for agent $i$ and $j$, respectively.

The proof can be found in Appendix A.

Further, we can show that:

Proposition $3 \frac{d e_{i}^{D}}{d \gamma}>0$ and $\frac{d e_{j}^{D}}{d \gamma}>0$ 
Proposition 3 implies that, as the strength of the externalities in academic performance (measured by $\gamma$ ) increases, so does the mean outcome of the group $E(x)=\frac{1}{2}\left(x_{i}+x_{j}\right)$ since everyone exerts higher effort.

Understanding the implications of relative utility on the dispersion of the outcomes is slightly more complicated. We start using equations 10 and 11 to derive the following convenient expression for the coefficient of variation of the outcomes, our measure of dispersion:

$$
C V(x)=\frac{S D(x)}{E(x)}=\frac{x_{i}-x_{j}}{x_{i}+x_{j}}
$$

As a first approximation, note that when $\gamma \rightarrow 0, e_{i}^{D} \rightarrow e_{j}^{D}$ and $C V\left(x^{D}\right) \rightarrow \frac{\epsilon}{1-\epsilon}>0$. As $\gamma \rightarrow 1, C V\left(x^{D}\right) \rightarrow 0$. Thus, the more students care about their relative performance the lower the dispersion in the outcomes. Intuitively, this result is generated by the concavity of the utility function by which student $j$, who is hit by the negative shock, is placed on a steeper segment of the utility function and, thus, cares more about performance. In fact, under some additional assumptions about the production function $f(\cdot)$, this result generalizes to the entire range of feasible values of $\gamma$. In Appendix A we describe such additional assumptions in detail. ${ }^{7}$

The following proposition describes the effect of relative utility evaluations on the mean and the dispersion of outcomes:

\section{Proposition 4}

(4.a) $\frac{\partial E\left(x^{D}\right)}{\partial \gamma} \geq 0$ for any admissible $\gamma \in[0,1)$;

(4.b) under the regularity conditions set out in Appendix $A \frac{\partial C V\left(x^{D}\right)}{\partial \gamma} \leq 0$ for any admissible $\gamma \in[0, \bar{\gamma})$

Proposition 4 shows that our simple model produces what is commonly termed peer effects also in the absence of any active interaction, simply by virtue of relative utility. We will maintain this case as the baseline scenario.

\footnotetext{
${ }^{7} \mathrm{~A}$ sufficient condition for $\frac{\partial C V(x)}{\partial \gamma}<0$ for all admissible values of $\gamma$ is that the third derivative $\frac{\partial^{3} f\left(e_{a}\right)}{\partial^{3} e_{a}}, \forall a=$ $i, j$ be positive and sufficiently large in absolute value.
} 


\subsection{Joint production}

In this section we modify the model under the assumption that students cooperate with each other in the production process. ${ }^{8}$ This could also be interpreted as a model of co-authorship, where each agent individually goes up for tenure or, alternatively, as a model of teamwork where individual performance is verifiable, effort is observed and the agents contribute to each other's output (Alchian \& Desmetz 1972, Holmstrom 1982, Kandel \& Lazear 1992).

Combining the definition of the production function in equation 2 and the structure of the shocks, we can define the following utility functions for agent $i$ and agent $j$ :

$$
\begin{aligned}
U_{i} & =\ln \left[g\left(e_{i}, e_{j}\right)-\gamma(1-\epsilon) g\left(e_{j}, e_{i}\right)\right]-e_{i} \\
U_{j} & =\ln \left[(1-\epsilon) g\left(e_{j}, e_{i}\right)-\gamma g\left(e_{i}, e_{j}\right)\right]-e_{j}
\end{aligned}
$$

Like in the decentralization case, optimal effort is determined in a non-strategic setting after observing the shocks according to the following first order conditions for the maximization of equations 13 and 14 ;

$$
\begin{array}{r}
\frac{\partial g\left(e_{i}^{C}, e_{j}^{C}\right)}{\partial e_{i}}=g\left(e_{i}^{C}, e_{j}^{C}\right)-\gamma(1-\epsilon) g\left(e_{j}^{C}, e_{i}^{C}\right) \\
(1-\epsilon) \frac{\partial g\left(e_{j}^{C}, e_{i}^{C}\right)}{\partial e_{j}}=(1-\epsilon) g\left(e_{j}^{C}, e_{i}^{C}\right)-\gamma g\left(e_{i}^{C}, e_{j}^{C}\right)
\end{array}
$$

where $e_{i}^{C}$ is the optimal effort of agent $i$ under joint production and similarly for $e_{j}^{C}$.

Using equations 15 and 16 , it is relatively easy to derive the following proposition, where $e_{i, j}^{D}$ is the optimal effort level under decentralization:

\section{Proposition 5}

(5.a) $e_{a}^{C}>e_{a}^{D}$ for any $a=\{i, j\}$;

(5.b) Average performance in the joint production scenario is larger than in decentralization:

\footnotetext{
${ }^{8}$ The term cooperation might also suggest a situation where agents maximize the sum of each other's utilities. This is not how we solve the model in this section, although in Section 2.5 we consider precisely that type of equilibrium as the planner's solution.
} 


$$
E\left(x^{C}\right)>E\left(x^{D}\right) \text {, where } x^{C}=\left[g\left(e_{i}^{C}, e_{j}^{C}\right),(1-\epsilon) g\left(e_{j}^{C}, e_{i}^{C}\right)\right] \text { and } x^{D}=\left[f\left(e_{i}^{D}\right),(1-\epsilon) f\left(e_{j}^{D}\right)\right]
$$

are the equilibrium outcomes under joint production and decentralization, respectively.

The proof, in Appendix A, is trivial given that the level of effort is larger under joint production than decentralization for both students, a result that rests exclusively on the existence of complementarities in the production function (i.e. $\frac{\partial^{2} g\left(e_{i}, e_{j}\right)}{\partial e_{i} \partial e_{j}}>0$ ).

Another interesting result of this model is described in the next proposition:

Proposition $6\left(x_{i}^{C}-x_{j}^{C}\right)<\left(x_{i}^{D}-x_{j}^{D}\right)$, hence, given Proposition 5.a and 5.b, $S D\left(x^{C}\right)<$ $S D\left(x^{D}\right)$ as well as $C V\left(x^{C}\right)<C V\left(x^{D}\right)$.

The formal proof is in Appendix A but the intuition of the result in proposition 6 is straightforward: the concavity in the utility function implies that the agent hit by the negative shock ( $j$ ) enjoys higher marginal returns (utility) from improved outcomes, hence she increases effort (relative to the decentralized equilibrium) more than her peer given the complementarity in the production function.

In sum, this section shows that, under joint production, students' outcomes are higher on average and less dispersed than under decentralization.

\subsection{Insurance}

The third and last mechanism of interaction that we consider is mutual insurance against idiosyncratic shocks to time or productivity, e.g. health shocks or random distractions (John H. Cochrane 1991, Barbara J. Mace 1991, Robert M. Townsend 1994). Under such circumstances the student would find herself in need of help to fill the gap of important teaching material. Given risk aversion, students have a desire to insure against such fluctuations in their time endowment (productivity) by exchanging notes or explanations of class material with classmates. We model such an exchange as a transfer of time or productivity $t$ between agents.

As already mentioned, we choose an extremely simple structure of the shocks but the implications of the model are robust to alternative assumptions. As long as there is some idiosyncratic variation in $t$, the main results are unchanged. 
For simplicity, we consider only the case of full insurance, where the students are perfectly able to smooth away the shocks to their time endowments. Moreover, given that our agents are ex-ante identical, we set identical Pareto weights. We also abstract from any issue of commitment (Stephen Coate \& Martin Ravallion 1993, Narayana R. Kocherlakota 1996, Fernando Alvarez \& Urban J. Jermann 2000, Ethan Ligon, Jonathan P. Thomas \& Tim Worrall 2000) but we will come back to this later in section 2.4. Notice, however, that even under limited commitment, students can achieve full insurance for some parametrization of the primitives of the model, for example when the punishment for deviating from a full insurance arrangement is large enough. Ultimately, the testable implications of our model would remain qualitatively unchanged also with partial insurance (Richard Blundell, Luigi Pistaferri \& Ian Preston 2008).

Under these assumptions, agents in our model choose their effort levels exclusively on the basis of the aggregate time endowment in the group. Hence, students solve the optimization problem by simply splitting equally the difference in their endowments. Moreover, since in our model the agents are ex-ante identical, the optimal level of effort is the same for both of them: $e_{i}^{I}=e_{j}^{I}=e^{I}$. Contrary to the previous cases (decentralization and joint production), in this particular setting it does not matter whether effort is determined before or after observing the shocks, apart from commitment issues. Formally,

$$
\begin{aligned}
U_{i} & =U_{j}=U=\ln [t f(e)-\gamma t f(e)]-e \\
t & =\left(1-\frac{\epsilon}{2}\right)
\end{aligned}
$$

The corresponding first order condition is:

$$
\frac{\partial f\left(e^{I}\right)}{\partial e^{I}}=f\left(e^{I}\right)
$$

and equilibrium performance is:

$$
x^{I}=\left(1-\frac{\epsilon}{2}\right) f\left(e^{I}\right) .
$$

Notice that $\gamma$, the parameter that measures reference utility considerations, does not appear 
in these first order conditions. This is due to the fact that under (full) insurance agents are identical both ex-ante and ex-post so that comparisons become meaningless. This has important implications on optimal effort, which is necessarily lower under mutual insurance than under decentralization (and, consequently, also compared to joint production) due to the fact that the within-group comparisons that induced higher effort in the benchmark case have now disappeared.

It is also trivial to see that, in this model, the ratio of marginal utilities $\frac{\partial U_{i}}{\partial e_{i}}=\frac{\partial U_{j}}{\partial e_{j}}$ is equal to 1 . This is a consequence of full insurance, as the ratio of the marginal utilities depends only on the Pareto weights, which, in our simple model, are identical for both agents. As such, given standard assumptions on the utility function, the ratio of the levels of performance $\frac{x_{i}^{I}}{x_{j}^{I}}$ is constant across states (and time).

This observation has a direct testable prediction: the vectors of performance outcomes of any two agents who engage in mutual full insurance should never cross, given that individual performance depends exclusively on the aggregate time endowment and the relative importance of the student in the group (the Pareto weights). ${ }^{9}$ In Section 4 , we take also this prediction to the empirical test.

We can, then, prove the following, where $e^{I}$ is the optimal effort level, common to both agents, under full insurance:

\section{Proposition 7}

(7.a) $e_{a}^{I}<e_{a}^{D}<e_{a}^{C}$ for any $a=\{i, j\}$, which immediately implies $E\left(x^{C}\right)>E\left(x^{D}\right)>E\left(x^{I}\right)$;

(7.b) $C V\left(x^{I}\right)<C V\left(x^{C}\right)<C V\left(x^{D}\right)$.

The proof is fairly straightforward and can, once again, be found in Appendix A. The intuition is that, under full insurance, effort is lower due to the lack of within-group heterogeneity that, with a reference based utility, generates the desire to excel. The result on dispersion is the combined outcome of the reduced impact of the idiosyncratic shocks, mechanically generated by the

\footnotetext{
${ }^{9}$ Such prediction would be however incorrect if the agents had heterogenous risk preferences (Sam SchullofferWohl 2008, Maurizio Mazzocco \& Shiv Saini 2009).
} 
insurance process, and the equalization of efforts among the agents. As we show in Appendix A. the variance is reduced at a faster rate than the mean performance, indeed in our simplified model with ex-ante homogeneous agents the (cross-sectional) variance of performance is equal to zero.

\subsection{Transition or the choice of the mechanism}

In this section we discuss the choice of the mode of interaction, which is based on a standard expected utility function defined over the two possible realizations of the shocks, i.e. $\left\{u_{i}, u_{j}\right\}=$ $\{0,-\epsilon\}$ and $\left\{u_{i}, u_{j}\right\}=\{-\epsilon, 0\}$. Notice that, since agents are ex-ante identical, they both share the same expected utility and the resulting choice of the mechanism will be unanimous.

We also assume that active social interactions, such as those required to produce jointly or to engage in mutual insurance, impose some utility cost and that such costs decrease with how well agents know each other. First, consider joint production and assume that the ability to cooperate depends on how well the students know each other, which is a positive function of the time they spend together. We model this as a (utility) cost that assumes the following form $c(m) \geq 0$, where $m$ is the number of times agents meet randomly and with $\frac{\partial c(m)}{\partial m}<0$. This cost function incorporates the idea that agents must pay some initial cost for getting to know each other. At some point the number of previous meetings is large enough to make the cost of cooperating lower than its benefits and students would, then, transit from the baseline scenario of complete decentralization to the joint production state.

A similar argument applies to insurance, as it takes time to get to know someone to the point that reciprocal monitoring and trust are sufficient to engage in mutual insurance. More formally, we describe the cost of insurance with a function $h(m)$, with $\frac{\partial h(m)}{\partial m}<0$. The function $h(m)$ could also be interpreted as a punishment or sanction function that describes the utility loss derived from deviating from the insurance scheme (Coate \& Ravallion 1993). Under such interpretation, the size of the punishment increases with the number of meetings, somehow capturing the idea that defaulting on someone we know better is more painful or more difficult.

Given that our agents are risk averse, they will have an incentive to renege on the insurance 
contract in the good state $(t=1)$ and, as such, the contract will have to be self enforcing or incentive compatible (Coate \& Ravallion 1993, Ligon, Thomas \& Worrall 2000). However, given the static nature of this simplified model, the only equilibrium would be to renege if the sanction is low. As students meet more often, they either find it harder to default on good friends or they develop the ability to punish deviating behaviors more effectively, so that, even under limited commitment, the full insurance allocation can be implemented for a sufficiently high level of $m$.

Consistently with our empirical application, where students initially do not know each other and are randomly allocated to teaching classes, we assume that decentralization requires no costs and is the baseline scenario.

Students select the mechanism that is associated with the highest level of expected utility as follows:

$$
\begin{aligned}
\text { Expected utility under decentralization: } E\left(U^{D}\right) & =\frac{1}{2} U\left(e_{u=0}^{D}\right)+\frac{1}{2} U\left(e_{u=-\epsilon}^{D}\right) \\
\text { Expected utility under joint production: } E\left(U^{C}\right) & =\frac{1}{2} U\left(e_{u=0}^{C}\right)+\frac{1}{2} U\left(e_{u=-\epsilon}^{C}\right)-c(m) \\
\text { Expected utility under mutual insurance: } E\left(U^{I}\right) & =U\left(e^{I}\right)-h(m)
\end{aligned}
$$

where $U\left(e_{u=0}^{D}\right)$ is the utility computed at the optimal effort level in decentralization under the good realization of the shock and similarly for the other expressions $\left(e_{u=-\epsilon}^{D}, e_{u=0}^{C}, e_{u=-\epsilon}^{C}\right.$ and $U\left(e^{I}\right)$ ), with superscripts indicating the interaction mode and subscripts the values of the shock. Recall than in the mutual insurance model optimal effort is independent of the shock.

The comparison of equations 21, 22, and 23 defines which mechanism governs the interactions among the students. When $m$ is sufficiently low, possibly zero, the costs associated with joint production or mutual insurance are larger than the benefits and students simply act in isolation according to our benchmark model of decentralized behavior. As $m$ increases, both $c(m)$ and $h(m)$ decrease until, for a sufficiently high $m$, either joint production or mutual insurance become the utility-maximizing mode of interaction.

The relative shape of the functions $c(m)$ and $h(m)$ defines which of the models, joint pro- 
duction or insurance, arises first. In fact, although we do not model this situation explicitly, it might very well be possible that, for some values of $m$, both joint production and mutual insurance coexist. Moreover, while it is obvious that in the absence of costs both joint production and mutual insurance would be preferred to decentralization, preferences over these last two mechanisms depend on the functional forms as well as on the size of the shock. ${ }^{10}$

Ultimately, the type of mechanism at work is an empirical matter and our analysis in Section 4 exploits the following testable implications to shed light on this precise issue:

$$
\begin{aligned}
& \text { If } \frac{\partial \operatorname{Var}(x)}{\partial m}<0 \text { and } \frac{\partial E(x)}{\partial m}>0 \Rightarrow \text { Joint production is the prevailing mechanism; } \\
& \text { If } \frac{\partial \operatorname{Var}(x)}{\partial m}<0 \text { and } \frac{\partial E(x)}{\partial m}<0 \Rightarrow \text { Insurance is the prevailing mechanism. }
\end{aligned}
$$

The reduction in the (within-group) dispersion of performances as a function of the time spent together indicates the existence of peer effects, while the relation between the number of meetings and average performance in the group allows to distinguish between joint production and insurance.

\subsection{Extensions}

In this section we briefly discuss three possible extensions to the theoretical setting described in the previous sections.

First, consider what happens if agents behave strategically, i.e. they internalize the effect of their choice of effort on their peer's optimal behavior (Yann Bramoullé \& Rachel Kranton 2007b- Yann Bramoullé \& Rachel Kranton 2007a). Here we only provide the intuition that our main results will be maintained in such a modified model but in Section Appendix C.1 we discuss this issue more formally.

Strategic behavior is motivated by two types of externality, one that arises from the reference point in the utility function and one from the complementarity in the production function.

\footnotetext{
${ }^{10}$ Joint production offers the advantage of exploiting the complementarities in the production function, hence in the absence of costs it would be preferred to decentralization. Similarly, mutual insurance reduces the variance of the outcomes and, given the concavity of the utility function, it dominates decentralization when $h(m)=0$.
} 
As far as the reference point is concerned, higher effort from one of the agents induces higher effort from the other, thus reducing one's utility because the reference point moves up. Such a mechanism leads to both agents exerting a lower level of effort in the strategic equilibrium compared to the non-strategic solution. However, the form of the utility function remains the same in all three interaction mechanisms that we consider (decentralization, joint production and insurance), therefore it does not modify the implications on the distribution of the outcomes across interactions models and within types of equilibrium, i.e. strategic versus non-strategic.

The second type of externality is generated by the complementarity in the production function and it only arises in the joint production model, as in all other cases agents produce in isolation and no complementarity can arise. Under joint production higher effort from one of the agents increases the productivity of the other, who will also increase effort, which in turn improves one's productivity.

Hence, in this framework there are two offsetting externalities: on the one hand, higher effort from one's peer raises the reference point, thus lowering utility; on the other hand, it improves productivity. The overall effect, compared to the non-strategic equilibrium, depends on the functional forms. Nevertheless, the externality in the utility function is common to all mechanisms so that, when comparing the distributions of the outcomes across mechanisms within the strategic framework, only the production externality matters. Hence, given that the production externality induces higher effort in joint production, there is no complementarity in the other two regimes, in a strategic equilibrium the implications on the mean outcome is reinforced. The same holds for dispersion, as the agent hit by the negative shock benefits more from the complementarity than the other.

The formal strategic solution of our model is further complicated by issues of existence and uniqueness of the equilibrium, which both depend on functional form assumptions. Nevertheless, given that the equilibrium exists and is unique, the intuition provided in this section is valid and our main results would be unchanged.

The next extension that we consider is a multiple-agents model, i.e. a model where groups 
are formed among more than just two students. ${ }^{11}$ In the decentralization mechanism, adding extra agents to one's group would simply lead to a different formula for the reference point in the utility function with no further modifications. Under joint production, the production function would have to be modified to incorporate all group members, however, as long as all cross derivatives in such a modified production function are non-negative, our qualitative implications would remain unchanged and the resulting model would simply be more complex without further insights. Finally, the results that we derive in the baseline insurance model with just two agents are still valid in a multi-agent framework, as long as the network's shape and informational structure remain unchanged. In fact, under such conditions, the marginal utilities of all group members would still be equalized in the same way as in the dyad. Furthermore, in a multiple-agents framework one might want to modify the cost functions for joint production and insurance $(c(m)$ and $h(m))$ to take into account the fact that active interaction with many agents might be costly and that the benefits might be decreasing so that the network has a bounded size or spans the entire set.

Finally, we briefly discuss a third modification of our model in which the joint production scenario is solved by maximizing the sum of the individual utilities (as in a planner problem). The results derived in Section 2.3 (as well as the proofs of Appendix A) assume that, in the joint production scenario, the two agents produce jointly but choose effort independently. An alternative and equally plausible assumption consists in maximizing the (possibly weighted) sum of the utilities of the agents, which is the case that we briefly discuss here and more in details in Appendix C.2.

We present this analysis with the help of simulations, since the set of necessary and sufficient conditions under this scenario are more cumbersome than those in the main text. For ease of comparison we show the simulations for the three proposed mechanisms, where the joint production model is solved by maximization of the sum of the agents' utilities. In such a framework some of our results depend on the specific functional form assumptions, however, as we show in details in Section Appendix C.2 and as shown in the simulation of Figure C1,

\footnotetext{
${ }^{11}$ We still maintain the assumption of homogeneous agents. Allowing for heterogeneous agents introduces the issue of endogenous group formation, thus making the model substantially more complicated.
} 
our main results are confirmed for a relatively standard parametrization of the problem. Figure C1 plots the average outcome and the dispersion of outcomes in the groups against the size of the shock and it shows that the mean performance under full insurance is lower than that in joint production and decentralization (no planner). Again confirming the previous results, the dispersion is lowest in full insurance.

The bottom panel of Figure C1 produces the ordering of expected utilities, for a given parametrization of the problem. Depending on the nature of the shock (and costs) students would want to move from decentralization to full insurance.

\section{The data}

In this section we describe the data we use in Section 4 to test the theoretical predictions of our models. The data come from the administrative archives of Bocconi University, an institution of higher education located in Milan, Italy ((Giacomo De Giorgi, Michele Pellizzari \& William Gui Woolston 2010, De Giorgi, Pellizzari \& Redaelli 2010)). The important feature of these data for the purpose of our application is that students are (repeatedly) randomly assigned to teaching classes for each of their compulsory courses.

More specifically, we will focus on two cohorts of students who first enrolled at Bocconi in the academic year 1999/00 and 2000/01. ${ }^{12}$ These students were offered 7 degree programs (majors), however, only 3 of them were large enough to require the splitting of lectures into more than one class: Economics, Management, Economics and Finance. ${ }^{13}$ The official duration of all programs was 4 years and, during the first two years, and for most of the third, all students were required to take a fixed sequence of compulsory courses. Afterwards students could choose elective subjects, following some program-specific guidelines. In order to avoid

\footnotetext{
${ }^{12}$ Although we have access to records for all students enrolled since 1989 and until 2009, we cannot choose a cohort that is too recent because some of the students might still be working towards the completion of their degrees. For the earlier cohorts we do not have information on the class identifiers, which are essential for our analysis. Moreover, Bocconi reformed the structure of its programs twice during the period covered by these data, first in 1999/00 and then 2001/02. Hence, to avoid comparing cohorts across different systems, we consider only students enrolled in their first year in 1999/00 and 2000/01.

${ }^{13}$ The other programs were Economics and Management of the Public Administration, Economics and Law, Law, Economics and Management in Arts, Culture and Communication.
} 
issues of endogenous selection, we exclude all elective courses from our analysis ad we focus exclusively on compulsory courses.

The compulsory curricula is summarized in Table 1, while more details are given in Table B1 in Appendix B. The table reports the number of compulsory courses (columns 1, 3 and 5) and the total number of lecturing hours (columns 2, 4 and 6) for each degree program and academic year. For example, Table 1 shows that students in Management take 8 compulsory courses during their first year for a total of 464 hours of lectures.

\section{[TABLE[1]}

The crucial institutional feature for our testing strategy is that students were allocated to the teaching classes according to a completely random procedure. ${ }^{14}$ The randomization was repeated at the beginning of each academic year, when each student was informed of her class identifier and was instructed to take all the lectures of the year in the class corresponding to her assigned identifier. Namely, students would take all the courses of the first year with the same random group of peers, then all the courses of the second year with a different random group and so on. Elective courses, which we do not consider in our analysis, were usually much smaller in size and could easily be taught in a single class.

The figures reported in Table 1 clearly show that students who were assigned to the same class ended up physically sitting in the same classroom for a considerable amount of time, thus suggesting that the random allocation process is an important determinant of the strength of students' interactions.

Students were allocated into several classes for the explicit purpose of maintaining adequate class sizes and to allow teachers to interact with the students in a more direct way. The yearly repetition of the random allocation was, instead, justified with the desire to encourage interactions among students. Bocconi has followed attentively the rule of randomly allocating

\footnotetext{
${ }^{14}$ The terms class and lecture often have different meanings in different countries and sometimes also in different schools within the same country. In most British universities, for example, lecture indicates a teaching session where an instructor - typically a full faculty member - presents the main material of the course. Classes are instead practical sessions where a teacher assistant solves problem sets and applied exercises with the students. At Bocconi there was no such distinction, meaning that the same randomly allocated groups were kept for both regular lectures and applied classes. Hence, in the remainder of the paper we use the two terms interchangeably.
} 
students to teaching classes so as to avoid clustering of students in some classes. Moreover, for organizational reasons, students allocated to a specific class were also taking most or all of their courses in exactly the same classroom. Overall, there are 12 classes per academic year (and cohort): 8 classes in Management, 2 in Economics and 2 in Economics\&Finance. The classes are approximately equal sized, although not exactly. ${ }^{15}$

\section{[TABLE[2]}

Table 2 reports some descriptive statistics on the 2,406 students that we eventually consider in our empirical exercise, broken down by degree program. The large majority of students are enrolled in the Management program, which attracts over $70 \%$ of them. The Economics program is chosen by about $10 \%$ of the students and the remaining $20 \%$ are in Economics\&Finance. There is a higher incidence of males $(58.5 \%)$ than females $(41.5 \%)$ in the student body, with gender differences being more pronounced in the Economics and Economics\&Finance programs. The majority $(68 \%)$ of students come from outside the province of Milan, the site of Bocconi. We also have information on the students' household income, which is recorded in 4 brackets at the time of enrollment for the purpose of determining tuition fees and eligibility for scholarships. About $22 \%$ of the students are in the highest of those brackets (approximately above 140 thousands USD). Average admission test scores and high school grades, normalized on a scale 0-100, suggest that the best students cluster in Economics and Economics\&Finance.

\section{[FIGURE[1]}

In Figure 1 we present evidence consistent with random allocation, as in De Giorgi, Pellizzari \& Woolston (2010) and De Giorgi, Pellizzari \& Redaelli (2010). The figure compares the distribution of some selected characteristics in the entire cohort and within the groups of peers of a randomly selected student in each of the three initial academic years. Specifically, the variables that we consider for the tests in Figure 1 are the entry test score (upper left graph),

\footnotetext{
${ }^{15}$ As discussed in De Giorgi, Pellizzari \& Woolston (2010), variation in class size is generated by mere logistic constraints, i.e. variation in the physical size of available classrooms.
} 
high school grade (upper right graph), the gender indicator (lower left graph), the indicator for high income (lower middle graph) and the dummy for residence outside Milan (lower right graph). As it is evident from the figure, the distributions all look very similar. Statistical tests also confirm such a visual impression. Table B2 in Appendix B reports Kolmogorov-Smirnov tests for the comparison of the distributions of the admission test scores in any possible pair of classes and any possible academic year. In the vast majority of cases we cannot reject the null of equality and only in 11 out of 180 statistics we can reject the null at the $10 \%$ level, so well below $10 \%$ of the cases. We have produced similar tests also for the distribution of high school grades as well as all the other characteristics considered in Figure 1 , using tests of proportions for those characteristics that take the form of simple dummy indicators (gender, high income students and residence outside Milan). Results are not reported for brevity but are available from the authors upon request.

In the empirical analysis of Section 4, we consider all possible pairs of students and compare mean grades and mean absolute grade differences (as a measure of dispersion of outcomes within the pair), both across pairs who are randomly allocated to the same classes more or less often and for the same pair over academic years. The focus on student pairs allows us to concentrate on the lowest possible level of group interaction and to directly compare our results with the implications of the model, that is also presented in a two-agents setting. For this purpose we construct all pairs of students who could possibly meet, i.e. all pairs of students who are in the same degree program and enrollment cohort. Eventually, we construct a dataset of over 800,000 pairs, whose descriptive statistics are reported in Table 3, it is here important to clarify that the data used for the empirical analysis contain one observation per pair per period so that if the pair $i, j$ appears in the data the symmetric pair $j, i$ does not. Specifically, since the random allocation is performed within degree program and cohort, only students within degree program and cohort cells can be allocated to the same class. Call $N_{c p}$ the number of students in cohort $c$ and degree program $p$, then the number of non-symmetric pairs generated by those students is $\frac{N_{c d}\left(N_{c d}-1\right)}{2}$. Table B3 in Appendix B shows the number of students in each $c d$ cell and the corresponding number of pairs. 
[TABLE[3]

All the descriptive statistics in Table 3 are consistent with the random allocation (within degree programs and cohorts) and the descriptives of the student body from Table $2,{ }^{16}$ The last row of Table 3 reports the mean value of a dummy indicator for whether the students in the pair are ever allocated to the same class and it shows that slightly less that $40 \%$ of the pairs ever met. Given the size of the degree programs and the number of random classes in each of them, this number varies considerably with a low 33\% in Management and a much larger $87 \%$ in Economics and Economics\&Finance.

The repeated randomization adopted by Bocconi generates as a byproduct the fact that some students met more often than others, a crucial feature for our empirical exercise in Section 4 . In Table 4 we describe the main variables that arise from such a repeated randomization process together with our key outcomes at the level of the student pairs.

\section{[TABLE 4]}

The first row of Table 4 reports the average number of courses any two students sit together by degree program and academic year. It is important to emphasize that, since this is meant to be an indicator of how many opportunities for interactions students have had, it is a cumulative variable, i.e. it measures the number of courses together in the current and in the past years. This is the reason why the number of courses together always increases from one year to the next. ${ }^{17}$ On average two random students would have sat 1.2 courses together by the end of their first year, 2.3 by their second year and 3.5 by the third. Notice that these averages combine pairs of students who never meet and others that meet repeatedly. Given the number of classes and courses in the different majors the above statistics become larger in Economics and in Economics\&Finance, i.e. 10-11 courses by the third year.

\footnotetext{
${ }^{16}$ The comparison of Table 2 and Table 3 in fact, can also be interpreted as a randomization test. One could derive most of the statistics in Table 3 from those in Table 2 , using the number of classes in each program and the size of each enrollment cohort (in each degree program).

${ }^{17}$ In the regression analysis of Section 4 this mechanical time effect is controlled for by a set of year and degree program dummies, which we always include in the control set.
} 
Since each course is taught for a different number of hours, the number of times students in the pair are randomly assigned to the same class defines the number of hours they end up sitting together in the same classroom (in the current and in the previous years). The average students pair spends approximately 70 hours together by the end of the first year, 135 by the second and over 200 by the third. Given the variation in the number of courses and their duration in hours (see Table 1), these statistics vary considerably across degree programs, with students in Economics and Economics\&Finance enjoying a lot more opportunities for interactions.

We also describe the evolution of both our main outcomes: the average and the dispersion of academic performance within groups and across academic years. Notice that our main explanatory variable (i.e. hours together) varies only across academic years for the same pair of student, hence we consider only one observation for each pair in each year. Consequently, we compute the average grade of the pair over all the compulsory courses of each academic year. As a measure of dispersion we consider the mean absolute grade difference, i.e. for each exam in each academic year we compute the absolute value of the difference in the grades of the students in the pair and we take the average of those absolute differences over all the courses of each academic year. ${ }^{18}$ Table 4 shows the basic characteristics of these variables, broken down by academic year and degree program. The average grade is similar across all programs and years and fluctuates around a mean of approximately 26/30 (B+), with a mean absolute difference of about $3.5 .^{19}$

The last row of Table 4 reports the means, by degree program and academic year, of the crossing indicator that we use in Section 4 to test the crossing property (see Section 2.3). Such an indicator is constructed by comparing the grade vectors of the two students in each pair in each academic year and verifying whether such vectors cross (at any point). In other words,

\footnotetext{
${ }^{18}$ In computing both the mean grade and the absolute mean grade difference of the pair we weight courses by their length, assigning a higher weight to longer courses, i.e. courses with more hours of lectures. For robustness, we have replicated all our results using unweighted outcomes obtaining virtually identical estimates. Such robustness checks are not reported for brevity but are available from the authors upon request.

${ }^{19}$ In Italy, university exams are graded on a scale 0 to 30 , with pass equal to 18 . Such a peculiar grading scale comes from historical legacy: while in primary, middle and high school students were graded by one teacher per subject on a scale 0 to 10 (pass equal to 6), at university each exam was supposed to be evaluated by a commission of three professors, each grading on the same 0-10 scale, the final mark being the sum of these three. Hence, 18 is pass and 30 is full marks. Apart from the scaling, the actual grading at Bocconi is performed as in the average US or UK university.
} 
the crossing indicator is equal to zero if one student consistently outperforms (or ties) the other in all the courses of the specific academic year. Otherwise, the grade vectors cross and the indicator takes value 1 . The probability of crossing, for any two students, ranges between $80 \%$ and $88 \%$, with the exception of the third year in the Economics program where it is equal to $68 \%$.

For completeness, in Table 5 we present the full extent of variation in our key independent variable, i.e. number of meetings or hours together. Given the academic structure of the curricula, the variation arises both between and within (over-time) programs. There are a number of sources of variation for our independent variable, all arising from the repeated random allocation in different teaching classes: variation across majors in a given year, as well as variation between pairs (cross-sectional and over time) and within pairs overtime. In particular, in the Management major about $65 \%$ of the possible pairs never meet, while those pairs who meet in the first and second year (1.4\%) sit together for about 850 hours, the few who meet every year $(0.2 \%)$ end up spending over 1,300 hours together. Any two students in Economics are quite likely to meet as there are only two classes. In fact only about $13 \%$ of the (potential) pairs never meet, while those who meet in year 1 and $2(12 \%)$ spend 880 hours in the same classroom, those who always meet (12\%) spend about 1,100 hours together. Consistently with the random allocation mechanism and similar class sizes, the meeting probabilities in the Economics\&Finance program are very similar to those in Economics. One can also show that as a result of the random allocation in two classes of similar sizes (Econ and Econ\&Finance) the distribution of meetings, i.e. the leftmost column in Table 5 should look pretty even and close to $12-13 \%$, which indeed is what we have in the data, an additional piece of evidence that is consistent with a successful random allocation.

\section{[TABLE[5]}




\section{Empirical Analysis}

In this section we analyze how the mean and the dispersion of academic outcomes within groups evolve as students spend more and more time together over the first three years of their academic tracks. Following our theoretical discussion in Section 2, the different mechanisms of social interactions have different implications for the relationships between number of meetings (hours) and the mean and dispersion of performance. Our main testable predictions are the following:

$$
\begin{aligned}
& \text { If } \frac{\partial \operatorname{Var}(x)}{\partial m}<0 \text { and } \frac{\partial E(x)}{\partial m}>0 \Rightarrow \text { Joint production is the mechanism; } \\
& \text { If } \frac{\partial \operatorname{Var}(x)}{\partial m}<0 \text { and } \frac{\partial E(x)}{\partial m}<0 \Rightarrow \text { Insurance is the mechanism. }
\end{aligned}
$$

where $m$ is a measure of the number of hours the pair of students spend together. Namely, as the number of interactions increases, we expect the average grade to increase if joint production is the prevailing mechanism, to decrease if it is insurance and to stay unchanged if the leading model is decentralization. The implications for dispersion are less clear cut, as we simply expect the dispersion of grades within pairs to decrease as the number of meeting or hours spent together increases when the prevailing mechanism is either joint production or insurance (or any combination of the two) and to remain unaffected if no transition takes place from decentralization to any of the other models. ${ }^{20}$

We test these predictions in Table 6, where we report the results of the following regressions:

$$
\begin{aligned}
& y_{i j c p t}=\alpha_{1}+\beta_{1} m_{i j t}+\gamma_{1 t}+\delta_{1 p}+\zeta_{1 c}+u_{i j c p t} \\
& y_{i j c p t}=\alpha_{2}+\beta_{2} m_{i j t}+\gamma_{2 t}+\eta_{i j}+e_{i j c p t}
\end{aligned}
$$

where $y_{i j c p t}$ is, alternatively, the mean grade or the mean (absolute) grade difference or the

\footnotetext{
${ }^{20}$ If we allow $\gamma$ to be increasing in $m$, i.e. the relative importance of one's peer performance increases in the number of meetings, we have that $\frac{\partial E\left(x^{D}\right)}{\partial m}>0$ and $\frac{\partial \operatorname{Var}\left(x^{D}\right)}{\partial m}<0$, as shown in Proposition 4.
} 
crossing indicator for pair $(i, j)$, in cohort $c$, degree program $p$ in year $t ; m_{i j t}$ measures the number of meetings or hours student $i$ and $j$ spent together on or before year $t$. Additionally, we control for year, degree program and cohort effects: $\gamma_{t}, \delta_{p}, \zeta_{c}$ respectively. Equation 25 is a slightly different specification of equation 24, where we include a pair fixed effect $\eta_{i j}$, which obviously also captures the degree program and cohort effects. $u_{i j c p t}$ and $v_{i j c p t}$ are random error terms.

The computation of the correct standard errors for equations 24 and 25 is particularly complicated and it requires to take proper account of three issues: (i) the panel dimension of the data (recall that we use one observation for each pair in each academic year); (ii) the pairwise structure of the observations and (iii) the semi-aggregate level of variation of our main regressor (hours together, $m_{i j t}$ ).

We take care of the first problem (the panel dimension) in equation 24 by applying the standard random effect transformation and in equation 25 by transforming the model in orthogonal deviations. ${ }^{21}$ In the standard textbook panel model, such transformations eliminate any serial correlation as well as any heteroskedasticity from the error term, so that the classic random or fixed effects estimators can be computed by simple ordinary least squares on the transformed data.

We can then take into account the other issues by clustering the standard errors of the transformed model. Specifically, we assume that the error term $e_{i j c p t}$ includes three additional components: a $\omega_{i}$ that induces serial correlation among all pairs where student $i$ is a member, a $\omega_{j}$ that induces serial correlation among all pairs with student $j$ as a member and a $\tau$ that is

\footnotetext{
${ }^{21}$ The standard random effect transformation subtracts from each variable in the model (both the dependent and each of the regressors) its within mean scaled by the factor $\theta=1-\sqrt{\frac{\sigma_{u}}{T \sigma_{\eta}+\sigma_{u}}}$. For example, the randomeffects transformed dependent variable is $y_{i j c p t}-\theta \bar{y}_{i j c p}$, where $\bar{y}_{i j c p}=T^{-1} \sum_{t=1}^{T} y_{i j c p}$ and $T=3$ in our application. Similarly for all the regressors. The estimates of $\sigma_{\eta}$ and $\sigma_{u}$ that we use for this transformation are the usual Swamy-Arora, also used by the command $x t r e g$ in Stata (P. A. V. B. Swamy \& S. S. Arora 1972). The transformation in orthogonal deviations consists in taking all variables in the model (both the dependent and each of the regressors) in differences from the within mean of all future values, scaling by a factor $c_{t}$ that guarantees homoskedasticity (in the absence of other error components). For example, the dependent variable of equation 25 transformed in orthogonal deviations is $\left[y_{i j c p t}-(T-t)^{-1} \sum_{k=t+1}^{T} y_{i j c p k}\right] c_{t}$, where $c_{t}^{2}=\frac{T-t}{T-t+1}$. Notice that in the model in orthogonal deviations the time dimension is reduced by one unit, which explains the different number of observations in columns 2 and 4 of Table 6 compared to columns 1 and 3 (and similarly in Table 7 and Table 9p.
} 
common to all pairs that share the same value of $m_{i j t} .{ }^{22}$ As long as these components are all additive, the above transformations (random effects and orthogonal deviations) do not affect the structure of the transformed error terms, which remain additive in the three components with the same (qualitative) variance-covariance matrices.

Hence, we take proper account of the pairwise nature of our data by clustering the standard errors of the ordinary least square estimates produced on the transformed models at the level of each individual student (i.e student $i$ and student $j$ in the pair). Additionally, since our main regressor of interest $\left(m_{i j t}\right)$ varies at a more aggregated level that the student pair (i.e. all pairs whose members are assigned to the same classes in current and previous years are associated to the same value of $m_{i j t}$ ) we face a standard Moulton problem (Brent R. Moulton 1990) and we further cluster the standard errors along a third dimension that corresponds to the exact cells of variation in $m_{i j t}$ (such cells of variation are those shown in Table 5). Technically, we perform such a three-level clustering using the procedure described in Colin A. Cameron, Douglas M. Miller \& Jonah B. Gelbach (2010).

The identification of the parameters in equations 24 and 25 is straightforward, given that the right hand side variable of interest $\left(m_{i j t}\right)$ is generated exclusively by the random allocation process, hence it is fully exogenous. Consistently with this interpretation, we obtain very similar estimates across the two specifications, although including the pair fixed effect $\eta_{i j}$ substantially improves efficiency.

Obviously, our measure of the strength of social interactions $\left(m_{i j t}\right)$ does not necessarily represent the true number of hours any two students spend together, either studying or engaging in other social activities. If we were able to observe such true measure of time together, we could use it in equations 24 and 25 instead of $m_{i j t}$. However, such a measure would be endogenous, as people may choose to spend more time with some classmates for reasons that are connected to academic performance. Hence, we could use $m_{i j t}$ as an instrument for real time together. Then, our results can be interpreted as the reduced form estimates of this hypothetical

\footnotetext{
${ }^{22}$ In order to simplify the notation, we omit to specify a subscript for $\tau$ as it is defined across the cells of variation of $m_{i j t}$ (those in Table 5p which are a complex combination of the students-degree-year dimensions of the data.
} 
IV framework.

Once again, we expect the effect of hours together on the pair's average performance (i.e $\beta_{s}$ for $\left.s=1,2\right)$ to be positive or negative depending on whether the prevailing mechanism is joint production or insurance, respectively. Our model does not exclude the possibility that both mechanisms operate simultaneously, so that we are really only able to test which one dominates.

\section{[TABLE 6]}

The results are reported in Table 6 and Table 7. In columns 1 and 2 of Table 6 we show the estimates of equations 24 and 25 with the mean grade of the pair as a dependent variable. For ease of interpretation both the dependent and the explanatory variables in these regressions are normalized within degree program and academic year, so that the estimated effects can be readily interpreted in terms of standard deviations. Namely, a one standard deviation increase in the number of hours together (approximately 240 hours) decreases mean performance by $2.2 \%$ to $2.7 \%$ of a standard deviation, corresponding to almost 0.05 grade points. It is also interesting to compare the average performance of pairs of students who are always assigned to the same class for all the three years of their track and pairs of students who are never assigned to the same class. These two types of student pairs are approximately 6.3 standard deviations apart in terms of hours together, hence their mean grades are $17 \%$ of a standard deviation apart in favor of the pair who never met, corresponding to almost 0.3 of a grade point. Consistently with the random nature of $m_{i j t}$, including pair fixed effects in the specification of the model only affects the coefficients marginally, while it substantially improves the precision of the estimates.

In columns 3 and 4 of Table 6 we report the estimates of equations 24 and 25 with our measure of grade dispersion as a dependent variable, i.e. the mean absolute grade difference of all the exams in each academic year. Results indicate that a one standard deviation increase in the number of hours together (approximately 240 hours) reduces the mean absolute grade difference by $1.2 \%$ of a standard deviation, corresponding to almost 0.02 grade points. The comparison of pairs at the extreme ends of the hours distribution indicates that those who 
are consistently assigned to the same class have a mean absolute grade difference lower by approximately $7.6 \%$ of a standard deviation or 0.11 grade points compared to those who never sit courses together.

While the negative relationship between dispersion in performance and the number of hours students spend together would be consistent with both insurance and joint production (or a combination of the two), the only mechanism that can rationalize the decline in average performance is insurance.

As discussed in the theoretical section, an additional test to assess the relevance of insurance motives relies on the time-series properties of students' performances, i.e. on whether students' grades in a pair cross each other. The logic of this crossing property is the following: consider a pair of students who perfectly share risk by insuring each other (full insurance), then they always exert the same level of effort, hence their outcomes should be either always identical, in case of homogenous agents (with the same Pareto weights), or never cross if agents are heterogeneous. Crossing outcomes are a signal of less than full insurance. This result has been shown in Cochrane (1991) and Mace (1991) and essentially restates that under full insurance the ratio of marginal utilities between any two agents is always constant and equal to the inverse of the ratio of the Pareto weights. Similar tests are produced in Tullio Jappelli \& Luigi Pistaferri (2006) and Mazzocco \& Saini (2009) in the consumption literature.

In our application, we expect students to insure more and more as they spend more and more time together, eventually approaching full insurance (see Section 2.4). We test this prediction by estimating equations 24 and 25 with the crossing indicator on the left hand side (linear probability model). The crossing indicator is a simple dummy variable equal to 1 if the vectors of exam grades of student $i$ and $j$ ever cross over the entire series of compulsory courses taken during year $t$. The results are reported in Table 7 .

[TABLE 7]

Results show that the likelihood of crossing decreases with the number of hours spent together and we take this as further evidence consistent with the insurance mechanism. Once 
again, the estimates are significant at conventional statistical levels only when conditioning on pair fixed effects (column 2). The magnitude of the effect is such that a one standard deviation increase in the number of hours together reduces the likelihood of crossing by 0.4 percentage points or $1.1 \%$ of a standard deviation. Alternatively, one can look at the difference between pairs of students who are always in the same class and pairs who are never in the same class, the latter being 2.5 percentage points more likely to cross their grades.

\subsection{Further Evidence}

A first simple robustness check of our results consists in investigating whether, for any spurious reasons, future classmates appear to be related in terms of academic outcomes. If that were to happen, our approach would be falsified from the start, as in none of our model we predict a relation between outcomes of students who have not met yet. In this light, we run a series of placebo regressions where we limit our sample to the first academic year (i.e. one observation for each pair) and we regress such outcome on an indicator for whether the pair will ever meet in the future two years. Results are reported in Table 8 and, consistently with the idea that future meetings should not be related to current outcomes, we find that all estimates are very close to zero and insignificant.

\section{[TABLE[8]}

A second piece of additional evidence addresses the following concern: although the number of hours together arises from the random allocation process, it might still be that our results on dispersion and grade crossing are simply the byproduct of the structure of our data. In fact, pairs with more hours together are more likely than others to have attended courses with the same teachers and, if teachers are heterogenous, this alone might reduce the variance of outcomes within pairs. Similarly, there could be cases in which such a reduction in the variance might also lead to a lower probability of crossing (although one would have to think about some very special cases of teacher heterogeneity). Note that these concerns bear no implications for the mean outcome of the pair as a function of the number of meetings. 
To address these issues, in Table 9 we augment equations 24 and 25 with a set of dummies for the classes assigned to each student in the pair $(i, j)$ in every academic year. Overall, there are 12 such dummies (one for each of the 8 classes in Management plus 2 classes in Economics and Economics\&Finance) for each student in the pair, for each academic year and each cohort, for a total of 144 dummies. Such class effects are meant to control for the potential bias due to unobservable factors at the class level, such as teacher quality, class size or class composition, that might be partially collinear with $m_{i j t}$. Results are qualitatively identical to those in Table 6 and Table 7. Also the magnitude of the estimates is very comparable, especially for grade crossing.

\section{[TABLE 9]}

The results in the previous section are consistent, within our framework, only with the insurance mechanism. As it is well known in the literature (Alvarez \& Jermann 2000), the level of informal insurance between two parties under limited commitment rests on three fundamental parameters, i.e. risk aversion, discount rate and correlation of shocks, plus the ability of the parties to monitor and enforce punishment for deviating behaviors. Although we do not directly observe any of these three parameters, one might think that gender is an important determinant of the degree of insurance under the assumption that reciprocal trust and monitoring are easier among same sex pairs.

We explore this idea in Table 10, where we report estimates of equation 25 for samples of pairs restricted to either same gender (row 1) or mixed gender (row 2) or both females (row 3) or both males (row 4). Results are remarkably similar across these groups and it only appears that females have a smaller negative effect on average performance when they interact among themselves.

\section{[TABLE[10]}

In Table 11 we further investigate heterogeneity in ability. Although the level of ability of a student in a pair should not matter for the degree of sustainable insurance in a pair, it 
is however true that it could determine the sharing rule, i.e. the more able of the pair gets allocated more time (or resources, our $t$ parameter in the model) in every state of the world (a higher Pareto weight). Therefore, in order to be consistent with the proposed mechanism, individual ability (which we measure with the standardized entry test) should be irrelevant for the relation between our first and second moments of the outcomes and the exogenous number of hours spent together.

Consistently with this interpretation, in Table 11 we find that, when estimating equation 25 on subsamples defined by ability quartiles of the two students in each pair, results are extremely homogeneous, especially as far as mean outcomes are concerned.

\section{[TABLE[11]}

\section{Alternative Mechanisms}

So far we have considered three plausible mechanisms that are able to explain what is commonly termed peer effects or social interactions in the literature. However, it might still be possible that other mechanisms are consistent with our empirical evidence. For example, one could construct a behavioral model where students get to know each other over time and divert their attention from studying to other more socializing activities (going out, partying, etc.). Such a mechanism could easily account for the drop in performance but would be hard pressed to explain the drop in the cross-sectional variance, as each student would be subject to her own shock. One possible way to adapt such a model to generate lower dispersion in outcomes consists in introducing some kind of preference for equality or conformity (Douglas B. Bernheim 1994, Akerlof 1997), whereby students dislike to perform differently from their friends. In this case students hit by different types of shocks would help each other. This, however, resembles quite closely our insurance model.

One might think as well that such alternative mechanism is particularly valid for males and lower ability students, as those students might have a higher inclination to partying. For this purpose, the evidence presented in the previous Section 4.1 (Tables 10 and 11) is particularly 
informative, as we find that the estimated effects are pretty homogeneous both across gender types and ability combinations. Such a lack of heterogeneity is consistent with insurance, as the insuring parties would not care about their relative ability but focus on the correlation of shocks and the ability to implement the informal contract.

Another possibility is that as students know each other better they care more about their relative performance, in our model this would mean that $\gamma$ is increasing in $m$. However, as shown in Proposition 4 , if that were the case the mean outcome should increase with the number of meeting which is the opposite of what we find in the data.

Further, the disruption model of Edward P. Lazear (2001), adequately modified, might be able to produce what we observe in the data. However, the Lazear's model of disruption naturally produces a negative correlation between group size and performance, while our results in Table 9 are not consistent with such a story. In fact when we control for class identifiers, which capture, among other things, the size of the class, we find almost the same results as those in the main Table 6. Moreover, the simplest disruption model would explain why the mean performance falls but would have very little to say regarding the cross-sectional variance, unless some further assumptions are made.

Finally, another alternative model could be one where students exhibit preferences for equality. Such a model could certainly explain the reduced dispersion in outcomes but it would generally display multiple equilibria, with students clustering around either high or low performance. There would be no reason for a generalized fall in performance. Furthermore, preferences for equality would not be enough to explain the observed relationship between the number of meetings and the average and the dispersion of performance. One would have to make further assumptions about how a student's interest for the performance of her friends varies with time spent together. The evidence in Table 11, seems to further reject such a model, as even in ex-ante homogenous pairs we have a reduction in performance, while that model would predict a clustering at a high level or low level, possibly depending on ability.

In general, it is always possible to propose a behavioral model that can explain our empirical findings (in fact, any empirical finding) and one possible reading of our contribution 
is precisely the possibility to explain the patter of social interactions on the basis of simple economic mechanisms, that are relatively standard and well established in the literature.

\section{Conclusions}

In this paper we propose a set of models of social interactions that generate testable implications capable of separating them empirically. In particular, we consider three possible mechanisms of interactions: i. a baseline scenario, where peer effects arise because of reference-based utility; ii. a model of joint production and; iii. one of mutual insurance against shocks to time or productivity. While all mechanisms predict a reduction in the dispersion of outcomes within groups (pairs) - what is commonly termed peer effects -, they differ in their implications for average performance, which, compared to the benchmark case, increases under cooperation and decreases with mutual insurance.

We take these simple predictions to the data using information on two cohorts of undergraduate Bocconi students, where we can exploit random variation in the number of meetings between students dictated by repeated random allocation into teaching classes. In this setting, the amount of time any two students spend together in the same lecturing classrooms is exogenous by definition and drives the transition from a decentralized model towards a model of insurance or cooperation. We find that the insurance motive dominates.

Such a result has clear policy implications: in order to increase average performance it would be beneficial to prevent students from sitting in the same class too often. Alternatively, the university could introduce incentives that limit the possibility to engage in mutual insurance and encourage cooperation or joint production.

Although we frame our theoretical discussion as well as the empirical application in the education setting, our analysis is more general and it applies to many different contexts, from teamwork to academic co-authorship to any environment where social interactions could be important. For example, if mutual insurance were proven to be the main mechanism of interaction in team production too, the design of incentive pay schemes, which is one of the fundamental 
issues in that literature, should take into account the possibility that workers may endogenously react to the introduction of such schemes by engaging in some kind of mutual insurance, thus undoing the expected effect on effort. Similarly, in the production of academic research people explicitly interact through co-authorship, although performance evaluation is typically carried out at the individual level, primarily via tenure decisions but also with the allocation of research funds and awards. This is also a setting that resembles our model very closely.

In the theoretical discussion we have assumed away agents' heterogeneity and endogenous group formation. Although such an assumption is consistent with our testing strategy, where students are randomly allocated to peers (and fixed effects are accounted for), we should emphasize that one important implication of our results is that an individual may choose different types of peers depending on whether the purpose of the group is cooperation or insurance. We also recognize that the process of group formation (Garance Genicot \& Debraj Ray 2003, Ballester, Calvó-Armengol \& Zenou 2006) is very important and that the interlink between such process and the choice of the interaction mode should be investigated thoroughly in future research. 


\section{References}

Akerlof, George A. 1997. "Social distance and social decisions.” Econometrica, 65(5): 10051027.

Alchian, Armen, and Harold Desmetz. 1972. "Production, Information costs, and Economic Organizations.” American Economic Review, 62: 777-795.

Alvarez, Fernando, and Urban J. Jermann. 2000. "Efficiency, Equilibrium, and Asset Pricing with Risk of Default.” American Economic Review, 68(4): 775-797.

Ballester, Coralio, Antoni Calvó-Armengol, and Yves Zenou. 2006. "Who's who in networks. Wanted: the key player.” Econometrica, 74(5): 1403-1417.

Bandiera, Oriana, Iwan Barankay, and Imran Rasul. 2009a. "Social Incentives in the Workplace.” Review of Economic Studies, 62: 777-795.

Bandiera, Oriana, Iwan Barankay, and Imran Rasul. 2009b. “Team Incentives: Evidence from a Field Experiment." mimeo UCL.

Bayer, Patrick, Randi Pintoff, and David Pozen. 2009. "Building criminal capital behind bars: Peer effect in juvenile corrections." Quarterly Journal of Economics, 124(1): 105147.

Bernheim, Douglas B. 1994. "A Theory of Conformity." The Journal of Political Economy, 102(5): 841-877.

Bisin, Alberto, Andrea Moro, and Giorgio Topa. 2009. “The Empirical Content of Models with Multiple Equilibria in Economies with Social Interactions.” mimeo New York University.

Blundell, Richard, Luigi Pistaferri, and Ian Preston. 2008. "Consumption Inequality and Partial Insurance.” American Economic Review, 98(5): 1887-1927. 
Bramoullé, Yann, and Rachel Kranton. 2007‥ "Risk Sharing across Communities." The American Economic Review, 97(2): pp. 70-74.

Bramoullé, Yann, and Rachel Kranton. 2007b. "Risk-sharing networks." Journal of Economic Behavior and Organization, 64: 275-294.

Bramoullé, Yann, Habiba Djebbari, and Bernard Fortin. 2009. "Identification of peer effects through social networks." Journal of Econometrics, 150(1): 41-55.

Brock, William A., and Steven N. Durlauf. 2001. "Interaction-based models." In $\underline{\text { Handbook }}$ of Econometrics. Vol. 5, , ed. James J. Heckman and Edward E. Leamer, Chapter 54, 3297-3380. Elsevier.

Cameron, Colin A., Douglas M. Miller, and Jonah B. Gelbach. 2010. "Robust Inference with Multi-way Clustering." Journal of Business and Economic Statistics.

Carrell, Scott, Bruce I. Sacerdote, and James E. West. 2010. "Beware of Economists Bearing Reduced Forms? An Experiment in How Not To Improve Student Outcomes.” mimeo UC Davis.

Coate, Stephen, and Martin Ravallion. 1993. "Reciprocity without commitment : Characterization and performance of informal insurance arrangements." Journal of Development Economics, 40(1): 1-24.

Cochrane, John H. 1991. "A simple test of consumption insurance.” Journal of Political Economy, 99(5): 957-976.

Cooley, Jane. 2009. "Desegregation and the achievement gap: Do diverse peers help?" mimeo University of Winsconsin-Madison.

De Giorgi, Giacomo, Michele Pellizzari, and Silvia Redaelli. 2010. "Identification of Social Interactions through Partially Overlapping Peer Groups.” American Economic Journal: Applied Economics, 2(2): 241-275. 
De Giorgi, Giacomo, Michele Pellizzari, and William Gui Woolston. 2010. "Class Size and Class Heterogeneity." Journal of the European Economic Association. forthcoming.

Falk, Armin, and Andrea Ichino. 2006. "Clean evidence on peer effects.” Journal of Labor Economics, 24(1): 39-57.

Genicot, Garance, and Debraj Ray. 2003. "Group Formation in Risk-Sharing Arrangements." Review of Economic Studies, 70(1): 87-113.

Graham, Bryan S. 2008. "Identifying social interactions through conditional variance restrictions.” Econometrica, 76(3): 643-660.

Holmstrom, Bengt. 1982. "Moral Hazard in Teams." The Bell journal of Economics, 13(2): 324-340.

Jackson, Matthew O. 2008. Social and Economic Networks. Princeton University press.

Jackson, Matthew O. 2009. "An Overview of Social Networks and Economic Applications." In The Handbook of Social Economics. , ed. Jess Benhabib, Alberto Bisin and Matthew O. Jackson. Elsevier Press. forthcoming.

Jappelli, Tullio, and Luigi Pistaferri. 2006. "Intertemporal choice and consumption mobility.” Journal of the European Economic Association, 4(1): 75-115.

Kandel, Eugene, and Edward P. Lazear. 1992. "Peer Pressure and Partnerships.” Journal of Political Economy, 100(4): 801-817.

Kocherlakota, Narayana R. 1996. "Implications of efficient risk sharing without commitment.” Review of Economic Studies, 63(4): 595-609.

Lazear, Edward P. 2001. "Educational Production." Quarterly Journal of Economics, 116(3): 777-803.

Ligon, Ethan, Jonathan P. Thomas, and Tim Worrall. 2000. "Mutual Insurance, Individual Savings and Limited Commitment." Review of Economic Dynamics, 3(2): 216-246. 
Mace, Barbara J. 1991. "Full insurance in the presence of aggregate uncertainty." Journal of Political Economy, 99(5): 928-956.

Manski, Charles F. 1993. "Identification of endogenous social effects: The reflection problem.” Review of Economic Studies, 60: 531-542.

Mas, Alexandre, and Enrico Moretti. 2009. "Peers at work." American Economic Review, 99(1): 112-145.

Mazzocco, Maurizio, and Shiv Saini. 2009. “Testing Efficient Risk Sharing with Heterogenous Risk Preferences.” mimeo UCLA.

Moffitt, Robert. 2001. "Policy interventions, low-level equilibria and social interactions." In Social Dynamics. , ed. Steven N. Durlauf and Peyton H. Young, Chapter 3. Cambridge: MIT Press.

Moulton, Brent R. 1990. "An Illustration of a Pitfall in Estimating the Effects of Aggregate Variables on Micro Units.” Review of Economics and Statistics, 72(2): 334-338.

Rosen, Sherwin. 1986. "Prizes and Incentives in Elimination Tournaments." The American Economic Review, 76(4): 701-715.

Schulloffer-Wohl, Sam. 2008. "Heterogeneous Risk Preferences and the Welfare Cost of Business Cycles.” Review of Economic Dynamics, 11(4): 761-780.

Swamy, P. A. V. B., and S. S. Arora. 1972. "The Exact Finite Sample Properties of the Estimators of Coefficients in the Error Components Regression Models.” Econometrica, 40(2): pp. 261-275.

Townsend, Robert M. 1994. "Risk and Insurance in Village India.” Econometrica, 62: 539-91. 


\section{Figures and Tables}

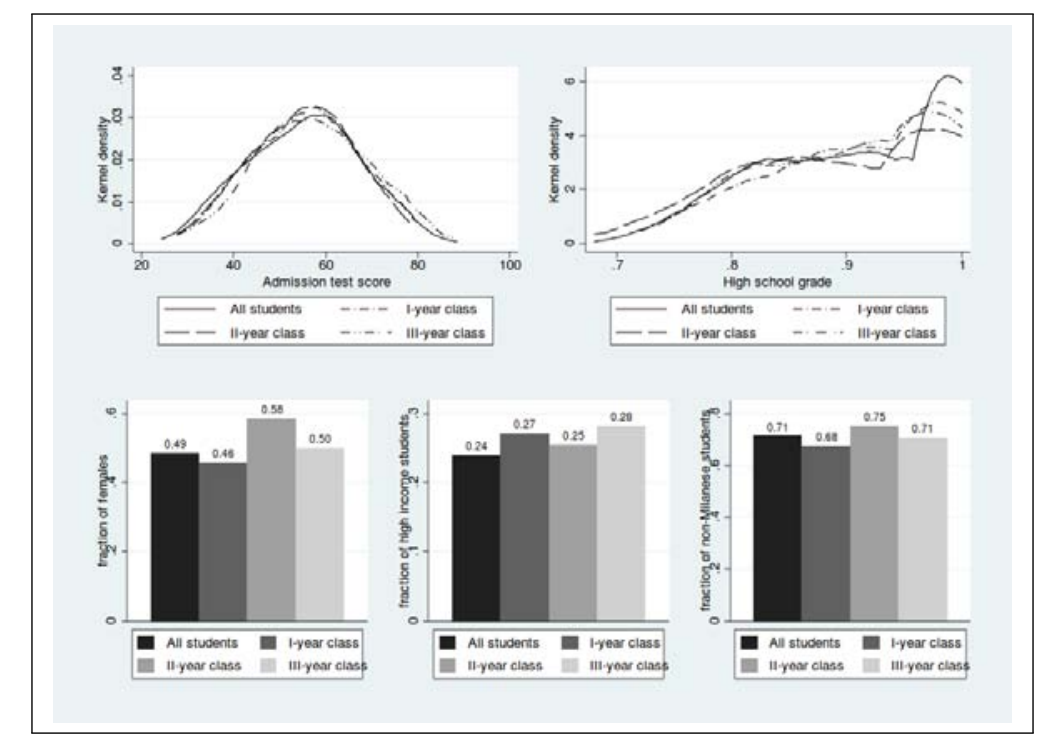

Figure 1: Distribution of selected variables within groups and in the population

Table 1: Compulsory curricula

\begin{tabular}{lcccccc}
\hline \hline & \multicolumn{2}{c}{ Management } & \multicolumn{2}{c}{ Economics } & \multicolumn{2}{c}{ Econ\&Finance } \\
& courses & hours & courses & hours & courses & hours \\
& {$[1]$} & {$[2]$} & {$[3]$} & {$[4]$} & {$[5]$} & {$[6]$} \\
\hline Academic year & & & & & & \\
Year 1 & 8 & 464 & 8 & 448 & 8 & 464 \\
Year 2 & 7 & 384 & 7 & 432 & 7 & 448 \\
Year 3 & 8 & 464 & 4 & 256 & 7 & 384 \\
Total & 23 & 1,312 & 19 & 1,136 & 22 & 1,296 \\
\hline \hline
\end{tabular}

Number of courses and hours by program. The detailed list of courses is in the appendix, Table B1. 
Table 2: Students' characteristics

\begin{tabular}{|c|c|c|c|c|}
\hline Variable & $\begin{array}{c}\text { All students } \\
\mathrm{N}=2,406 \\
\text { mean } \\
\text { (std.dev.) }\end{array}$ & $\begin{array}{c}\text { Management } \\
\mathrm{N}=1,713 \\
\text { mean } \\
\text { (std.dev.) }\end{array}$ & $\begin{array}{c}\text { Economics } \\
\mathrm{N}=224 \\
\text { mean } \\
\text { (std.dev.) }\end{array}$ & $\begin{array}{c}\text { Econ\&Finance } \\
\mathrm{N}=496 \\
\text { mean } \\
\text { (std.dev.) }\end{array}$ \\
\hline $1=$ female & $\begin{array}{c}0.415 \\
-\end{array}$ & $\begin{array}{c}0.451 \\
-\end{array}$ & $\begin{array}{c}0.388 \\
-\end{array}$ & 0.299 \\
\hline $1=$ original residence outside $\operatorname{Milan}^{a}$ & $\begin{array}{c}0.676 \\
-\end{array}$ & $\begin{array}{c}0.664 \\
-\end{array}$ & $\begin{array}{c}0.638 \\
-\end{array}$ & 0.736 \\
\hline $1=$ highest income bracket ${ }^{b}$ & $\begin{array}{c}0.223 \\
-\end{array}$ & $\begin{array}{c}0.235 \\
-\end{array}$ & $\begin{array}{c}0.246 \\
-\end{array}$ & 0.171 \\
\hline Admission test score ${ }^{c}$ & $\begin{array}{l}65.213 \\
(15.80)\end{array}$ & $\begin{array}{l}63.702 \\
(15.54)\end{array}$ & $\begin{array}{l}69.369 \\
(16.80)\end{array}$ & $\begin{array}{l}68.742 \\
(15.36)\end{array}$ \\
\hline High school leaving grade ${ }^{d}$ & $\begin{array}{l}89.542 \\
(10.19)\end{array}$ & $\begin{array}{l}88.721 \\
(10.30)\end{array}$ & $\begin{array}{l}89.991 \\
(10.89)\end{array}$ & $\begin{array}{c}92.324 \\
(8.89)\end{array}$ \\
\hline
\end{tabular}

${ }^{a}$ Coded to 1 if the student's residence is outside the province of Milan (which is where the university is located).

${ }^{b}$ Coded to 1 if the student's household income falls in the highest bracket for the determination of fees.

${ }^{c}$ Normalized between 0 and 100 .

${ }^{d}$ Normalized between 0 and 100 (pass $=60$ )

Table 3: Characteristics of the student pairs

\begin{tabular}{|c|c|c|c|c|}
\hline (Num. of pairs) & $\begin{array}{c}\text { All } \\
(800,935)\end{array}$ & $\begin{array}{c}\text { Management } \\
(732,808)\end{array}$ & $\begin{array}{c}\text { Economics } \\
(13,161)\end{array}$ & $\begin{array}{c}\text { Econ\&Finance } \\
(54,966)\end{array}$ \\
\hline $1=$ same sex & 0.512 & 0.507 & 0.521 & 0.581 \\
\hline $1=$ both males & 0.317 & 0.303 & 0.372 & 0.493 \\
\hline $1=$ both females & 0.195 & 0.204 & 0.149 & 0.088 \\
\hline 1=both from outside Milan ${ }^{a}$ & 0.449 & 0.443 & 0.391 & 0.538 \\
\hline 1=both from Milan ${ }^{a}$ & 0.113 & 0.115 & 0.142 & 0.072 \\
\hline $1=$ both high income ${ }^{b}$ & 0.053 & 0.055 & 0.056 & 0.029 \\
\hline $1=$ none high income ${ }^{b}$ & 0.592 & 0.586 & 0.582 & 0.686 \\
\hline$A b s\left(\right.$ test $_{i}-$ test $\left._{j}\right) /$ test $^{c}$ & 0.234 & 0.236 & 0.229 & 0.214 \\
\hline$A b s\left(H S_{i}-H S_{j}\right) / H S^{c}$ & 0.125 & 0.127 & 0.133 & 0.101 \\
\hline $1=$ ever met & 0.375 & 0.328 & 0.874 & 0.873 \\
\hline
\end{tabular}

The table reports the means of the indicated variables.

${ }^{a}$ Coded to 1 if both student's residence is inside (outside) the province of Milan (which is where the university is located).

${ }^{b}$ Coded to 1 if the household incomes of both (none) students falls in the highest bracket for the determination of fees.

${ }^{c}$ The absolute difference in test scores and high school grades between the two students in the pair are normalized by the average test score and high school grade among all students in the same enrollment cohort and degree program. 


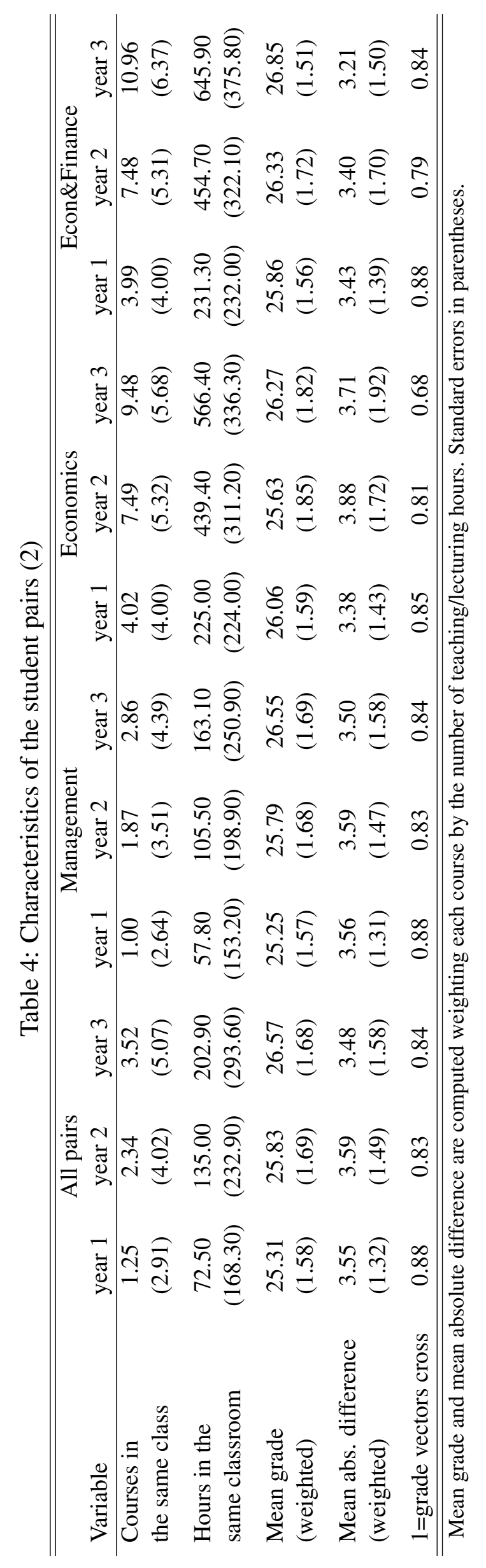


Table 5: Distribution of hours together

\begin{tabular}{lcccccc}
\hline \hline & \multicolumn{2}{c}{ Management } & \multicolumn{2}{c}{ Economics } & \multicolumn{2}{c}{ Econ\&Finance } \\
Meetings & $\%$ & Hours & $\%$ & Hours & $\%$ & Hours \\
\hline Never & 67.16 & 0 & 12.61 & 0 & 12.71 & 0 \\
Year 1 & 9.55 & 464 & 12.83 & 448 & 12.64 & 464 \\
Year 2 & 9.51 & 384 & 12.34 & 432 & 12.48 & 448 \\
Year 3 & 9.52 & 464 & 12.46 & 256 & 12.38 & 384 \\
Year 1\&Year 2 & 1.37 & 848 & 12.6 & 880 & 12.37 & 912 \\
Year 1\&Year 3 & 1.35 & 928 & 12.46 & 704 & 12.42 & 848 \\
Year 2\&Year 3 & 1.35 & 848 & 12.37 & 688 & 12.58 & 832 \\
Always & 0.19 & 1312 & 12.33 & 1136 & 12.42 & 1296 \\
\hline \hline
\end{tabular}

Table 6: Time together and academic outcomes

\begin{tabular}{lcccc}
\hline \hline & \multicolumn{2}{c}{ Mean grade } & \multicolumn{2}{c}{ Mean abs. grade difference } \\
& {$[1]$} & {$[2]$} & {$[3]$} & {$[4]$} \\
\hline Hours in the same class & -0.022 & $-0.027 * * *$ & -0.013 & $-0.012 * *$ \\
& $(0.015)$ & $(0.011)$ & $(0.008)$ & $(0.005)$ \\
& & & & \\
Student pairs' fixed effects & no & yes & no & yes \\
& & & & \\
Observations & $2,402,805$ & $1,601,870$ & $2,402,805$ & $1,601,870$ \\
Number of pairs & 800,935 & 800,935 & 800,935 & 800,935 \\
\hline \hline
\end{tabular}

Both the dependent variables and the explanatory variables are normalized within degree program and academic year cells. All regressions include academic year dummies. The specifications in columns 1 and 3 also include dummies for enrollment cohort and degree program.

The standard errors are three-way clustered at the level of each student in the pair and the frequency of their meetings.

* significant at $10 \%$;* significant at $5 \%$; ** significant at $1 \%$. 
Table 7: The crossing property

\begin{tabular}{lcc}
\hline \hline & \multicolumn{2}{c}{ 1=grade vectors cross } \\
& {$[1]$} & {$[2]$} \\
\hline Hours in the same class & -0.002 & $-0.004^{* * *}$ \\
& $(0.003)$ & $(0.001)$ \\
& & \\
Student pairs' fixed effects & no & yes \\
& & \\
Observations & $2,402,805$ & $1,601,870$ \\
Number of pairs & 800,935 & 800,935 \\
\hline \hline
\end{tabular}

The explanatory variables are normalized within degree program and academic year cells. All regressions include academic year dummies. The specifications in column 1 also includes dummies for enrollment cohort and degree program. The standard errors are three-way clustered at the level of each student in the pair and the frequency of their meetings. * significant at $10 \%$;* significant at 5\%; *** significant at $1 \%$.

Table 8: Placebo regressions

\begin{tabular}{|c|c|c|c|}
\hline & $\begin{array}{c}\text { Mean grade } \\
\text { [1] }\end{array}$ & $\begin{array}{l}\text { Mean abs. grade difference } \\
{[2]}\end{array}$ & $\begin{array}{c}1=\text { crossing } \\
{[3]}\end{array}$ \\
\hline $1=$ meet anytime in the future & $\begin{array}{c}0.001 \\
(0.002)\end{array}$ & $\begin{array}{l}-0.003 \\
(0.003)\end{array}$ & $\begin{array}{c}0.001 \\
(0.001)\end{array}$ \\
\hline Number of pairs & 800,935 & 800,935 & 800,935 \\
\hline
\end{tabular}


Table 9: Robustness check with class effects

\begin{tabular}{lcccc}
\hline \hline & \multicolumn{2}{c}{ Mean abs. grade difference } & \multicolumn{2}{c}{ 1=grade vectors cross } \\
& {$[1]$} & {$[2]$} & {$[3]$} & {$[4]$} \\
\hline Hours in the same class & $-0.014^{*}$ & $-0.015^{* * *}$ & -0.002 & $-0.004 * * *$ \\
& $(0.008)$ & $(0.002)$ & $(0.003)$ & $(0.001)$ \\
& & & & \\
Student pairs' fixed effects & no & yes & no & yes \\
Class fixed effects & yes & yes & yes & yes \\
& & & & \\
Observations & $2,402,805$ & $1,601,870$ & $2,402,805$ & $1,601,870$ \\
Number of pairs & 800,935 & 800,935 & 800,935 & 800,935 \\
\hline \hline
\end{tabular}

In columns 1 and 2 both the dependent variables and the explanatory variables are normalized within degree program and academic year cells. In columns 3 and 4 only the explanatory variables are normalized. All regressions include academic year dummies. The specifications in columns 1 and 3 also include dummies for enrollment cohort and degree program.

The standard errors are three-way clustered at the level of each student in the pair and the frequency of their meetings.

* significant at $10 \%$;* significant at $5 \%$;** significant at $1 \%$.

Table 10: Heterogeneity of the effects across gender compositions

\begin{tabular}{|c|c|c|c|}
\hline & $\begin{array}{c}\text { Mean Grade } \\
{[1]}\end{array}$ & $\begin{array}{l}\text { Mean abs. grade difference } \\
\text { [2] }\end{array}$ & $\begin{array}{c}\text { Observations } \\
\text { [3] }\end{array}$ \\
\hline \multicolumn{4}{|c|}{ Gender composition of the pair: } \\
\hline Same sex & $\begin{array}{c}-0.028 * * \\
(0.011)\end{array}$ & $\begin{array}{c}-0.014 * * \\
(0.006)\end{array}$ & 820,334 \\
\hline Mixed sex & $\begin{array}{c}-0.027 * * \\
(0.011)\end{array}$ & $\begin{array}{c}-0.011 * * \\
(0.005)\end{array}$ & 781,536 \\
\hline Both females & $\begin{array}{l}-0.014^{*} \\
(0.008)\end{array}$ & $\begin{array}{c}-0.021 * * \\
(0.008)\end{array}$ & 312,150 \\
\hline Both males & $\begin{array}{c}-0.034 * * * \\
(0.013)\end{array}$ & $\begin{array}{l}-0.008 \\
(0.006)\end{array}$ & 508,184 \\
\hline
\end{tabular}

The table reports the fixed-effects estimates of the effect of hours together on the outcome restricting the sample to type of pairs indicated in the first column.

The standard errors are three-way clustered at the level of each student in the pair and the frequency of their meetings. across the two samples.

$*$ significant at $10 \%$; * significant at $5 \%$; ** significant at $1 \%$. 
Table 11: Heterogeneity of the effects across gender compositions

\begin{tabular}{|c|c|c|c|c|c|}
\hline \multicolumn{6}{|c|}{ PANEL A: Mean grade } \\
\hline & & \multicolumn{4}{|c|}{ Student $i$} \\
\hline & \multirow{4}{*}{$\begin{array}{c}\text { quartiles: } \\
\text { first }\end{array}$} & first & second & third & fourth \\
\hline \multirow{7}{*}{ 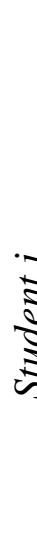 } & & $-0.029 * *$ & $-0.026 * *$ & $-0.028 * *$ & $-0.031 * *$ \\
\hline & & $(0.013)$ & $(0.012)$ & $(0.011)$ & $(0.013)$ \\
\hline & & - & $-0.025^{*}$ & $-0.024 * *$ & $-0.032 * * *$ \\
\hline & \multirow[t]{2}{*}{ second } & - & $(0.013)$ & $(0.010)$ & $(0.012)$ \\
\hline & & - & - & $-0.022 * *$ & $-0.024 * *$ \\
\hline & \multirow[t]{2}{*}{ third } & - & - & $(0.010)$ & $(0.011)$ \\
\hline & & - & - & - & $-0.033 * *$ \\
\hline & fourth & - & - & - & $-(0.015)$ \\
\hline \multicolumn{6}{|c|}{ PANEL B: Mean abs. grade difference } \\
\hline \multicolumn{6}{|c|}{ Student $i$} \\
\hline \multirow{9}{*}{ 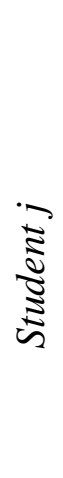 } & quartiles: & first & second & third & fourth \\
\hline & first & -0.005 & -0.008 & $-0.014 * *$ & $-0.016 * *$ \\
\hline & & $(0.010)$ & $(0.008)$ & $(0.007)$ & $(0.007)$ \\
\hline & second & - & -0.007 & $-0.013 *$ & -0.008 \\
\hline & & & $(0.007)$ & $(0.007)$ & $(0.007)$ \\
\hline & third & - & - & -0.016 & $-0.018 * * *$ \\
\hline & & & & $(0.011)$ & $(0.006)$ \\
\hline & fourth & - & - & - & -0.013 \\
\hline & & & & & $(0.008)$ \\
\hline
\end{tabular}

The table reports the fixed-effects estimates of the effect of hours together on the outcome, restricting the sample to pairs of students in the indicated quartiles of the ability distribution. Ability is measured by the entry test score. Quartiles ordered in ascending order.

The standard errors are three-way clustered at the level of each student in the pair and the frequency of their meetings.

* significant at $10 \%$; * significant at $5 \%$; *** significant at $1 \%$. 


\section{Appendix A Proofs}

\section{Proof of Proposition 1 .}

Proof. By contradiction, suppose $e_{i}>e_{j}$, then $\frac{\partial f\left(e_{i}\right)}{\partial e_{i}}<\frac{\partial f\left(e_{j}\right)}{\partial e_{j}}$ and from the first order conditions in equations 10 and 11 .

$$
\begin{aligned}
f\left(e_{j}\right)-\frac{\gamma}{1-\epsilon} f\left(e_{i}\right) & >f\left(e_{i}\right)-\gamma(1-\epsilon) f\left(e_{j}\right) \\
f\left(e_{j}\right)[1+\gamma(1-\epsilon)] & >f\left(e_{i}\right)\left[1+\frac{\gamma}{1-\epsilon}\right]
\end{aligned}
$$

For equations $\mathrm{A} 1$ and $\mathrm{A} 2$ to be jointly satisfied with $\frac{\partial f\left(e_{i}\right)}{\partial e_{i}}<\frac{\partial f\left(e_{j}\right)}{\partial e_{j}}$, it must be that

$$
\begin{aligned}
1+\gamma(1-\epsilon) & >1+\frac{\gamma}{1-\epsilon} \\
1-\epsilon & >\frac{1}{1-\epsilon}
\end{aligned}
$$

which is impossible with $\epsilon<1$.

\section{Proof of proposition 2.}

Proof. Subtracting the first order conditions in equations 10 and 11 from each others yields:

$$
x_{i}-x_{j}=\frac{1}{1+\gamma}\left[\frac{\partial f\left(e_{i}\right)}{\partial e_{i}}-(1-\epsilon) \frac{\partial f\left(e_{j}\right)}{\partial e_{j}}\right]>0
$$

which is positive, given that $\frac{\partial f\left(e_{i}\right)}{\partial e_{i}}>\frac{\partial f\left(e_{j}\right)}{\partial e_{j}}$.

\section{Proof for proposition 3 ,}

Proof. The proof is in two steps. First, we show that $\frac{d e_{i}}{d \gamma}$ and $\frac{d e_{j}}{d \gamma}$ must have the same sign. Take the total differential of the first order conditions in equations 10 and 11 and rearrange terms to obtain:

$$
\begin{aligned}
{\left[\frac{\partial f\left(e_{i}\right)}{\partial e_{i}}-\frac{\partial^{2} f\left(e_{i}\right)}{\partial^{2} e_{i}}\right] \frac{d e_{i}}{d \gamma} } & =(1-\epsilon) f\left(e_{j}\right)+\gamma(1-\epsilon) \frac{\partial f\left(e_{j}\right)}{\partial e_{j}} \frac{d e_{j}}{d \gamma} \text { (A5) } \\
(1-\epsilon)\left[\frac{\partial f\left(e_{j}\right)}{\partial e_{j}}-\frac{\partial^{2} f\left(e_{j}\right)}{\partial^{2} e_{j}}\right] \frac{d e_{j}}{d \gamma} & =f\left(e_{i}\right)+\gamma \frac{\partial f\left(e_{i}\right)}{\partial e_{i}} \frac{d e_{i}}{d \gamma}
\end{aligned}
$$

which cannot be jointly satisfied if $\frac{d e_{i}}{d \gamma}$ and $\frac{d e_{j}}{d \gamma}$ have different signs. Second, we show that $\frac{d e_{i}}{d \gamma}>0$ (or alternatively that $\frac{d e_{j}}{d \gamma}>0$ ). Combining the two first order 
conditions in equations 10 and 11 yields:

$$
\begin{aligned}
{\left[\frac{\partial f\left(e_{i}\right)}{\partial e_{i}}-\frac{\partial^{2} f\left(e_{i}\right)}{\partial^{2} e_{i}}\right] \frac{d e_{i}}{d \gamma} } & =(1-\epsilon)+\frac{\gamma(1-\epsilon) \frac{\partial f\left(e_{j}\right)}{\partial e_{j}} f\left(e_{i}\right)}{\frac{\partial f\left(e_{j}\right)}{\partial e_{j}}-\frac{\partial^{2} f\left(e_{j}\right)}{\partial^{2} e_{j}}}+ \\
& +\frac{\gamma^{2}(1-\epsilon) \frac{\partial f\left(e_{j}\right)}{\partial e_{j}} \frac{\partial f\left(e_{i}\right)}{\partial e_{i}}}{\frac{\partial f\left(e_{j}\right)}{\partial e_{j}}-\frac{\partial^{2} f\left(e_{j}\right)}{\partial^{2} e_{j}}} \frac{d e_{i}}{d \gamma}
\end{aligned}
$$

which shows that $\frac{d e_{i}}{d \gamma}>0$ if

$$
\begin{gathered}
\frac{\partial f\left(e_{i}\right)}{\partial e_{i}}-\frac{\partial^{2} f\left(e_{j}\right)}{\partial^{2} e_{i}}-\gamma^{2}(1-\epsilon) \frac{\frac{\partial f\left(e_{j}\right)}{\partial e_{j}} \frac{\partial f\left(e_{i}\right)}{\partial e_{i}}}{\frac{\partial f\left(e_{j}\right)}{\partial e_{j}}-\frac{\partial^{2} f\left(e_{j}\right)}{\partial^{2} e_{j}}}>0 \\
\frac{\partial f\left(e_{i}\right)}{\partial e_{i}}\left[1-\gamma^{2}(1-\epsilon) \frac{\frac{\partial f\left(e_{j}\right)}{\partial e_{j}}}{\frac{\partial f\left(e_{j}\right)}{\partial e_{j}}-\frac{\partial^{2} f\left(e_{j}\right)}{\partial^{2} e_{j}}}\right]-\frac{\partial^{2} f\left(e_{j}\right)}{\partial^{2} e_{i}}>0
\end{gathered}
$$

which is in fact positive.

\section{Proof of proposition 4}

Proof. The first result $\left(\frac{E(x)}{\partial \gamma} \geq 0\right)$ comes immediately from the fact that both $e_{i}$ and $e_{j}$ increase with $\gamma$. To find the sufficient conditions under which $\frac{C V(x)}{\partial \gamma} \leq 0$, compute the variation in $C V(x)$ as $\gamma$ changes:

$$
\begin{aligned}
\frac{d C V(x)}{d \gamma} & =\frac{2}{\left(x_{i}+x_{j}\right)^{2}}\left[x_{j} \frac{d x_{i}}{d \gamma}-x_{i} \frac{d x_{j}}{d \gamma}\right] \\
& =\frac{2(1-\epsilon)}{\left(x_{i}+x_{j}\right)^{2}}\left[f\left(e_{j}\right) \frac{\partial f\left(e_{i}\right)}{\partial e_{i}} \frac{d e_{i}}{d \gamma}-f\left(e_{i}\right) \frac{\partial f\left(e_{j}\right)}{\partial e_{j}} \frac{d e_{j}}{d \gamma}\right]
\end{aligned}
$$

It is easy to show that in equilibrium $f\left(e_{j}\right) \frac{\partial f\left(e_{i}\right)}{\partial e_{i}}>f\left(e_{i}\right) \frac{\partial f\left(e_{j}\right)}{\partial e_{j}}$, which implies that the necessary condition to have $\frac{d C V(x)}{d \gamma}<0$ is $\frac{d e_{j}}{d \gamma}>\frac{d e_{i}}{d \gamma}$ and the higher the difference between $\frac{d e_{j}}{d \gamma}$ and $\frac{d e_{i}}{d \gamma}$ the more likely that $\frac{d C V(x)}{d \gamma}<0$. In particular, it can be shown that if $\frac{\partial^{3} f(\cdot)}{\partial^{3} e_{a}}>0$ then $\frac{d e_{j}}{d \gamma}>\frac{d e_{i}}{d \gamma}$. In fact, the sufficient condition to have $\frac{d C V(x)}{d \gamma}<0$ essentially states that $\frac{\partial^{3} f(\cdot)}{\partial^{3} e_{a}}$ must be positive and large enough:

$$
\frac{\partial^{3} f(\cdot)}{\partial^{3} e_{a}}>>0 \Rightarrow \frac{d e_{j}}{d \gamma}>>\frac{d e_{i}}{d \gamma} \Rightarrow \frac{d C V(x)}{d \gamma}>0
$$

\section{Proof of proposition 5 .}

Proof. i) By contradiction, suppose $e_{i}^{C}<e_{i}^{D}$ and look at how the first order 
condition in equation 15 changes when effort changes from $e_{i}^{C}$ to $e_{i}^{D}$ :

$$
\begin{array}{r}
\frac{\partial^{2} g\left(e_{i}, e_{j}\right)}{\partial^{2} e_{i}}=\frac{\partial g\left(e_{i}, e_{j}\right)}{\partial e_{i}} \\
-\gamma(1-\epsilon) \frac{\partial g\left(e_{j}^{C}, e_{i}^{C}\right)}{\partial e_{i}^{C}}\left(e_{i}^{D}-e_{i}^{C}\right)
\end{array}
$$

If $e_{i}^{C}<e_{i}^{D}$, the LHS of this equation would be negative and the RHS would be positive, which is impossible. Hence, it must be that $e_{i}^{C}>e_{i}^{D}$. Similarly for $e_{j}^{C}<e_{j}^{D}$.

ii) given $i$ ) and the complementarity assumption.

Proof of proposition 6 .

Proof. Subtracting the first order conditions in equations 15 and 16 to one another, yields:

$$
x_{i}^{C}-x_{j}^{C}=\frac{1}{1+\gamma}\left[\frac{\partial g\left(e_{i}^{C}, e_{j}^{C}\right)}{\partial e_{i}^{C}}-(1-\epsilon) \frac{\partial g\left(e_{j}^{C}, e_{i}^{C}\right)}{\partial e_{j}^{C}}\right]
$$

Take the total differential of $x_{i}^{C}-x_{j}^{C}$ from this expression when $e_{i}^{D}$ increases to $e_{i}^{C}$ and $e_{j}^{D}$ increases to $e_{j}^{C}$ :

$$
\begin{aligned}
d\left(x_{i}^{C}-x_{j}^{C}\right)= & \frac{\partial^{2} g\left(e_{i}^{C}, e_{j}^{C}\right)}{\partial^{2} e_{i}^{C}} d e_{i}+\frac{\partial^{2} g\left(e_{i}, e_{j}\right)}{\partial e_{i} \partial e_{j}} d e_{j}- \\
& -(1-\epsilon) \frac{\partial^{2} g\left(e_{j}^{C}, e_{i}^{C}\right)}{\partial^{2} e_{j}^{C}} d e_{j}-(1-\epsilon) \frac{\partial^{2} g\left(e_{j}, e_{i}\right)}{\partial e_{j} \partial e_{i}} d e_{i} \\
= & d e_{i}\left[\frac{\partial^{2} g\left(e_{i}^{C}, e_{j}^{C}\right)}{\partial^{2} e_{i}^{C}}-(1-\epsilon) \frac{\partial^{2} g\left(e_{j}, e_{i}\right)}{\partial e_{j} \partial e_{i}}\right]- \\
& -d e_{j}\left[\frac{\partial^{2} g\left(e_{i}, e_{j}\right)}{\partial e_{i} \partial e_{j}}-(1-\epsilon) \frac{\partial^{2} g\left(e_{j}^{C}, e_{i}^{C}\right)}{\partial^{2} e_{j}^{C}}\right]<0
\end{aligned}
$$

which, given that $d e_{i}>0, d e_{j}>0, \frac{\partial^{2} g\left(e_{i}, e_{j}\right)}{\partial^{2} e_{i}}<0$ and $\frac{\partial^{2} g\left(e_{i}, e_{j}\right)}{\partial e_{i} \partial e_{j}}>0$, is negative.

\section{Proof of proposition 7 .}

Proof. Simply comparing the first order conditions for the insurance model in equation 19 and the decentralization model in equations 10 or 11 shows that $e^{I}<$ $e_{i}^{D}$. It, then, follows that $E\left(x^{I}\right)<E\left(x^{D}\right)<E\left(x^{C}\right)$. Under full insurance the performance of both students is identical, hence $C V\left(x^{I}\right)=0$. 
Appendix B Additional empirical results 
Table B1: Academic Structure

\begin{tabular}{|c|c|c|c|c|}
\hline Degree program & Year & Courses & Hours & Subject area \\
\hline \multirow[t]{23}{*}{ Management } & \multirow[t]{8}{*}{ First year } & Management I & 64 & Management \\
\hline & & Accounting I & 48 & Management \\
\hline & & Management II & 64 & Management \\
\hline & & Microeconomics & 64 & Economics \\
\hline & & Mathematics & 80 & Quantitative \\
\hline & & Private Law & 64 & Law \\
\hline & & Public Law & 32 & Law \\
\hline & & Economic History & 48 & Other \\
\hline & \multirow[t]{7}{*}{ Second year } & Accounting II & 64 & Management \\
\hline & & Public management & 32 & Management \\
\hline & & Organization theory & 64 & Management \\
\hline & & Macroeconomics & 64 & Economics \\
\hline & & Statistics & 64 & Quantitative \\
\hline & & Mathematics for Finance & 32 & Quantitative \\
\hline & & Commercial Law & 64 & Law \\
\hline & \multirow[t]{8}{*}{ Third year } & Marketing & 64 & Management \\
\hline & & Innovation management & 64 & Management \\
\hline & & Corporate finance & 64 & Management \\
\hline & & Managerial accounting & 64 & Management \\
\hline & & Management of informational systems & 32 & Management \\
\hline & & Strategic management & 64 & Management \\
\hline & & Economics of financial markets & 64 & Economics \\
\hline & & Public Economics & 48 & Economics \\
\hline \multirow[t]{19}{*}{ Economics } & \multirow[t]{8}{*}{ First year } & Management I & 64 & Management \\
\hline & & Accounting & 48 & Management \\
\hline & & Microeconomics & 64 & Economics \\
\hline & & Mathematics & 80 & Quantitative \\
\hline & & Private Law & 64 & Law \\
\hline & & Private Law & 32 & Law \\
\hline & & Economic history & 48 & Other \\
\hline & & Sociology & 48 & Other \\
\hline & \multirow[t]{7}{*}{ Second year } & Management II & 64 & Management \\
\hline & & Economics of financial markets & 48 & Economics \\
\hline & & Economic analysis & 64 & Economics \\
\hline & & Macroeconomics & 64 & Economics \\
\hline & & Mathematics for economics & 64 & Quantitative \\
\hline & & Statistics & 64 & Quantitative \\
\hline & & Commercial law & 64 & Law \\
\hline & \multirow[t]{4}{*}{ Third year } & Public Economics & 64 & Economics \\
\hline & & International economic policy & 64 & Economics \\
\hline & & Data analysis & 64 & Quantitative \\
\hline & & Econometrics & 64 & Quantitative \\
\hline \multirow[t]{22}{*}{ Econ\&Finance } & \multirow[t]{8}{*}{ First year } & Management I & 64 & Management \\
\hline & & Accounting & 48 & Management \\
\hline & & Economics of financial intermediation & 64 & Economics \\
\hline & & Microeconomics & 64 & Economics \\
\hline & & Mathematics & 80 & Quantitative \\
\hline & & Private Law & 64 & Law \\
\hline & & Public Law & 32 & Law \\
\hline & & Economic History & 48 & Other \\
\hline & \multirow[t]{7}{*}{ Second year } & Securities market & 64 & Economics \\
\hline & & Macroeconomics & 64 & Economics \\
\hline & & Monetary economics & 64 & Economics \\
\hline & & Public economics & 64 & Economics \\
\hline & & Statistics & 64 & Quantitative \\
\hline & & Mathematics for finance & 64 & Quantitative \\
\hline & & Commercial law & 64 & Law \\
\hline & \multirow[t]{7}{*}{ Third year } & Management II & 64 & Management \\
\hline & & Corporate finance & 64 & Management \\
\hline & & International monetary economics & 48 & Economics \\
\hline & & Applied economics & 48 & Economics \\
\hline & & Global banking & 48 & Economics \\
\hline & & Banking & 64 & Economics \\
\hline & & Financial market law & 48 & Law \\
\hline
\end{tabular}


Table B2: Kolmogorov-Smirnov tests of the equality of the distribution of test scores across classes.

\begin{tabular}{|c|c|c|c|c|c|c|c|c|}
\hline & Cohort: & & 2000 & & & & 2001 & \\
\hline & Year: & first & second & third & & first & second & third \\
\hline \multicolumn{9}{|l|}{ Economics } \\
\hline & Class $1 \& 2$ & 0.327 & 0.479 & 0.774 & & 0.93 & 0.704 & 0.477 \\
\hline \multicolumn{9}{|c|}{ Econ\&Finance } \\
\hline & Class $1 \& 2$ & 0.55 & 0.757 & 0.804 & & 0.627 & 0.276 & 0.888 \\
\hline \multicolumn{9}{|l|}{ Management } \\
\hline \multicolumn{9}{|l|}{2000 first year } \\
\hline & Classes & 2 & 3 & 4 & 5 & 6 & 7 & 8 \\
\hline & 1 & 0.401 & 0.982 & 0.537 & 0.293 & 0.591 & 0.885 & 0.721 \\
\hline & 2 & . & 0.683 & 0.978 & 0.307 & 0.413 & 0.738 & 0.256 \\
\hline & 3 & . & . & 0.853 & 0.495 & 0.818 & 0.898 & 0.902 \\
\hline & 4 & . & . & . & 0.386 & 0.792 & 0.847 & 0.602 \\
\hline & 5 & . & . & . & . & 0.483 & 0.325 & 0.456 \\
\hline & 6 & . & . & . & . & . & 0.968 & 0.643 \\
\hline & 7 & . & . & . & . & . & . & 0.943 \\
\hline \multicolumn{9}{|c|}{2000 second year } \\
\hline & Classes & 2 & 3 & 4 & 5 & 6 & 7 & 8 \\
\hline & 1 & 0.578 & 0.037 & 0.291 & 0.053 & 0.397 & 0.686 & 0.176 \\
\hline & 2 & . & 0.193 & 0.287 & 0.192 & 0.674 & 0.947 & 0.64 \\
\hline & 3 & . & . & 0.057 & 0.986 & 0.567 & 0.197 & 0.249 \\
\hline & 4 & . & . & . & 0.068 & 0.303 & 0.522 & 0.425 \\
\hline & 5 & . & . & . & . & 0.479 & 0.201 & 0.306 \\
\hline & 6 & . & . & . & . & . & 0.497 & 0.61 \\
\hline & 7 & . & . & . & . & . & . & 0.535 \\
\hline \multicolumn{9}{|l|}{2000 third year } \\
\hline & Classes & 2 & 3 & 4 & 5 & 6 & 7 & 8 \\
\hline & 1 & 0.53 & 0.342 & 0.41 & 0.905 & 0.862 & 0.32 & 0.353 \\
\hline & 2 & . & 0.971 & 0.991 & 0.823 & 0.912 & 0.868 & 0.096 \\
\hline & 3 & . & . & 1 & 0.632 & 0.864 & 0.822 & 0.127 \\
\hline & 4 & . & . & . & 0.6 & 0.824 & 0.924 & 0.188 \\
\hline & 5 & . & . & . & . & 0.93 & 0.223 & 0.361 \\
\hline & 6 & . & . & . & . & . & 0.381 & 0.253 \\
\hline & 7 & . & . & . & . & . & . & 0.061 \\
\hline \multicolumn{9}{|l|}{2001 first year } \\
\hline & Classes & 2 & 3 & 4 & 5 & 6 & 7 & 8 \\
\hline & 1 & 0.985 & 0.781 & 0.122 & 0.439 & 0.161 & 0.345 & 0.763 \\
\hline & 2 & . & 0.525 & 0.304 & 0.77 & 0.432 & 0.282 & 0.902 \\
\hline & 3 & . & . & 0.133 & 0.389 & 0.156 & 0.329 & 0.13 \\
\hline & 4 & . & . & . & 0.808 & 0.631 & 0.009 & 0.253 \\
\hline & 5 & . & . & . & . & 0.574 & 0.041 & 0.571 \\
\hline & 6 & . & . & . & . & . & 0.027 & 0.352 \\
\hline & 7 & . & . & . & . & . & . & 0.09 \\
\hline \multicolumn{9}{|l|}{2001 second year } \\
\hline & Classes & 2 & 3 & 4 & 5 & 6 & 7 & 8 \\
\hline & 1 & 0.707 & 0.099 & 0.419 & 0.107 & 0.538 & 0.286 & 0.106 \\
\hline & 2 & . & 0.426 & 0.347 & 0.498 & 0.863 & 0.835 & 0.669 \\
\hline & 3 & . & . & 0.091 & 0.221 & 0.854 & 0.281 & 0.355 \\
\hline & 4 & . & . & . & 0.607 & 0.271 & 0.295 & 0.093 \\
\hline & 5 & . & . & . & . & 0.228 & 0.549 & 0.367 \\
\hline & 6 & . & . & . & . & . & 0.905 & 0.545 \\
\hline & 7 & . & . & . & . & . & . & 0.637 \\
\hline \multicolumn{9}{|l|}{2001 third year } \\
\hline & Classes & 2 & 3 & 4 & 5 & 6 & 7 & 8 \\
\hline & 1 & 0.377 & 0.352 & 0.796 & 0.21 & 0.709 & 0.879 & 0.994 \\
\hline & 2 & . & 0.652 & 0.542 & 0.542 & 0.842 & 0.483 & 0.871 \\
\hline & 3 & . & . & 0.157 & 0.644 & 0.4 & 0.304 & 0.419 \\
\hline & 4 & . & . & . & 0.348 & 0.772 & 0.951 & 0.938 \\
\hline & 5 & . & . & . & . & 0.132 & 0.363 & 0.438 \\
\hline & 6 & . & . & . & . & . & 0.585 & 0.922 \\
\hline & 7 & . & . & . & . & . & . & 0.75 \\
\hline
\end{tabular}

The table reports the p-values of pairwise Klomogorov-Smirnov test for the equality of the distributions of entry test scores in all available pairs of classes within the same cohort-degree program-academic year cells. 
Table B3: Number of students and student pairs

\begin{tabular}{lccc}
\hline \hline Degree & \multicolumn{3}{c}{ Cohort } \\
program & $1999-2000$ & 2000-2001 & Total \\
\hline \multicolumn{4}{c}{ Panel A: Number of students } \\
Management & 865 & 848 & 1,713 \\
Economics & 139 & 85 & 224 \\
Econ\&Finance & 249 & 220 & 469 \\
Total & 1,253 & 1,153 & 2,406 \\
\hline \multicolumn{4}{c}{ Panel B: Number of pairs } \\
Management & 373,680 & 359,128 & 732,808 \\
Economics & 9,591 & 3,570 & 13,161 \\
Econ\&Finance & 30,876 & 24,090 & 54,966 \\
Total & 414,147 & 386,788 & 800,935 \\
\hline
\end{tabular}




\section{Appendix C Extensions to the model}

\section{Appendix C.1 Strategic Interactions}

We consider in this section the possibility of strategic interactions in our set-up. For this purpose, we revisit the equilibria under decentralization, joint production and full insurance, assuming that each student in the pair internalizes the effect of one's effort on peer's effort.

Decentralization. With strategic behavior, the first order conditions of equations 10 and 11 in section 2.1 change into the following:

$$
\begin{aligned}
& \frac{\partial f\left(e_{i}^{D S}\right)}{\partial e_{i}}=f\left(e_{i}^{D S}\right)-\gamma(1-\epsilon) f\left(e_{j}^{D S}\right)+\gamma(1-\epsilon) \frac{\partial f\left(e_{j}^{D S}\right)}{\partial e_{j}} \frac{\partial e_{j}}{\partial e_{i}} \\
& (1-\epsilon) \frac{\partial f\left(e_{j}^{D S}\right)}{\partial e_{j}}=(1-\epsilon) f\left(e_{j}^{D S}\right)-\gamma f\left(e_{i}^{D S}\right)+\gamma \frac{\partial f\left(e_{i}^{D S}\right)}{\partial e_{i}} \frac{\partial e_{i}}{\partial e_{j}}
\end{aligned}
$$

where $e_{i}^{D S}$ indicated the optimal effort level of agent $i$ (or $j$ ) under decentralization with strategic behavior.

It is, then, easy to see that $e_{a}^{D S}<e_{a}^{D}, \forall i, j$. We can also prove a modified version of Proposition 1, that takes strategic behavior into account. The proof proceeds analogously to the one of Proposition 1 by contradiction. ${ }^{23}$

Joint Production Under joint production higher effort from one of the agents increases the productivity of the other, who will then also increase effort, which in turn improves one's productivity. Hence, in this framework there are two offsetting externalities: on the one hand higher effort from one's peer raises the reference point, thus lowering utility, on the other hand it improves productivity. The overall effect, compared to the non-strategic equilibrium, depends on the functional forms. Nevertheless, the externality in the utility function is common to all mechanisms so that, when comparing the distributions of the outcomes across mechanisms within the strategic framework, only the production externality matters. Hence, since the production externality unambiguously induces higher effort, compared to decentralization or insurance where complementarity is ruled out, in a strategic equilibrium the implications on the mean outcome is reinforced. The same holds for dispersion, as the agent hit by the negative shock benefits more from the complementarity than the other.

Eventually, a modified version of Proposition 5 would still hold with $e_{a}^{C S} \geq e_{a}^{D S}, \forall a=i, j$, while the relationship between $e_{a}^{C S}$ and $e_{a}^{C}$ depends on functional form assumptions (where $e_{a}^{C S}$ is the optimal effort level of agent $a$ under joint production with strategic behavior).

Full Insurance. In the full insurance scenario with strategic interactions the results are also in line with those presented in the main text. If we take the first order conditions in section 2.3 and we modify them to take explicit account of the strategic interactions we obtain the following:

$$
\frac{\partial f\left(e^{I S}\right)}{\partial e}=\frac{f\left(e^{I}\right)}{1+\frac{\partial e_{-a}}{\partial e_{a}}}
$$

\footnotetext{
${ }^{23}$ Notice that in this framework existence and uniqueness of the equilibrium depend on the specific functional forms. However, conditional on the equilibrium existence and uniqueness, the modified version of Proposition 1 can be proven.
} 
where $e^{I S}$ is the optimal effort level (common to both agents) under full insurance with strategic behavior.

Given that $\frac{\partial e_{-a}}{\partial e_{a}}>0 \forall a=i, j$, then $e^{I S}<e^{I}$. It is then immediate to show that, even with strategic interactions, the level of effort is lowest under full insurance compared to any of the other mechanisms.

\section{Appendix C.2 Social Planner}

The results derived in the main text and the proofs of Appendix A assume that, in the joint production scenario, the two agents take each other's actions as given, while still producing jointly. This might be a questionable assumption, which, however, does not fundamentally change our results but simplifies the mathematical conditions and proofs. In what follows we show that, even when we consider a social planner equilibrium in the joint production scenario (i.e. an equilibrium that fully internalizes the externalities), the main implications of our simple model still stand.

We present this analysis with the help of simulations, since the set of necessary and sufficient conditions under this particular allocation are more cumbersome than those in the main text. For ease of comparison we show the simulation results for the three proposed mechanisms: i. decentralization; ii. joint production (planner's problem) and iii. full insurance, where in the joint production scenario we solve the programming problem under a social planner.

The simulation results we report in this section are based upon the following parametric assumptions on the production functions:

$$
\begin{aligned}
f\left(e_{a}\right) & =t_{a} \alpha e_{a}^{\beta} \quad \forall a=i, j \\
g\left(e_{i}, e_{j}\right) & =t_{i}\left[\alpha e_{i}^{\rho}+(1-\alpha) e_{j}^{\rho}\right]^{\frac{\beta}{\rho}}
\end{aligned}
$$

with $0<\beta<\rho<1$ to preserve standard properties of the production function. We solve for the equilibria under the assumption that $\alpha=.6, \gamma=.5, \rho=.95$, and $\beta=.5$ while we let the magnitude of the shock vary between a minor shock of $1 \%$ of the time endowment and a large shock of $15 \%$ of the individual endowment.

Figure $\mathrm{C} 1$ shows that the allocations that we obtain from this simulation mimic those presented in the main text. In fact, no matter the magnitude of the shock, the average performances (upper panel) can still be ranked in ascending order, with full insurance yielding the lowest level, followed by decentralization and, then, the joint production case. As one would expect, average performance decreases with the magnitude of the shock. Also, the results on dispersion (middle panel) do not differ from those in the main text. In choosing the mechanism one would have to look at the utility comparison as in the bottom panel of Figure C1, where we also take into account the cost of producing jointly $c(m)$ or insurance $h(m)$ fixed at two arbitrary levels for the graphical representation. In this latter figure one can notice that the sum of utilities, in this particular scenario, suggests that, depending on the magnitude of the shock, one would move from decentralization to joint production to full insurance as the shock becomes bigger. 


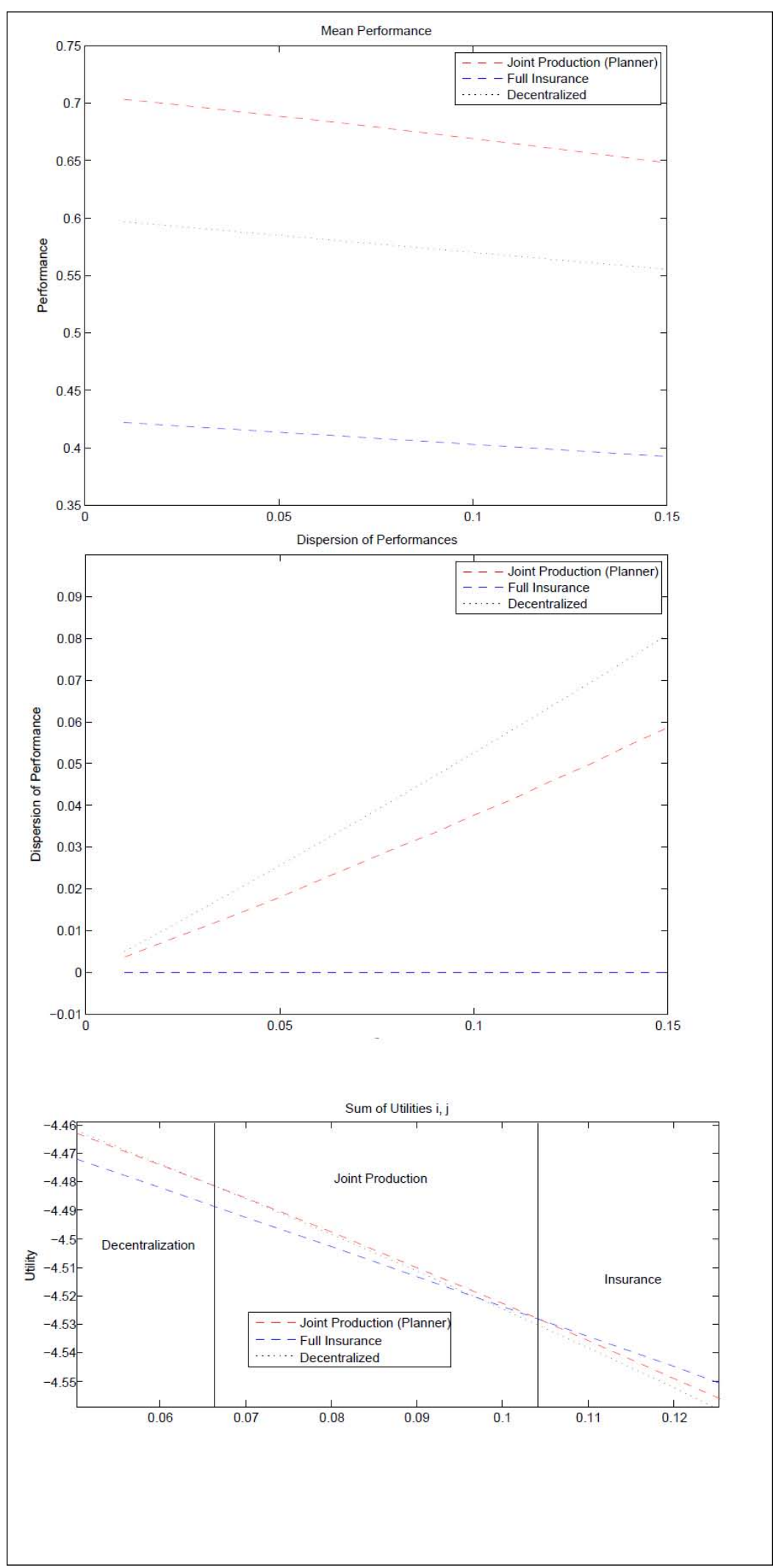

Figure C1: Simulation results 